\title{
Endoscopic diagnosis and management of nonvariceal upper gastrointestinal hemorrhage (NVUGIH): European Society of Gastrointestinal Endoscopy (ESGE) Guideline - Update 2021
}

Authors

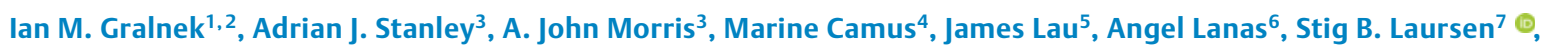
Franco Radaelli ${ }^{8}$, loannis S. Papanikolaou ${ }^{9}$, Tiago Cúrdia Gonçalves ${ }^{10,11,12}$, Mario Dinis-Ribeiro ${ }^{13,14}$, Halim Awadie ${ }^{1} \odot$, Georg Braun ${ }^{15}$, Nicolette de Groot ${ }^{16}$, Marianne Udd ${ }^{17}$, Andres Sanchez-Yague ${ }^{18,19}$, Ziv Neeman ${ }^{2,20}$, Jeanin E. van Hooft $^{21}$

\section{Institutions}

1 Institute of Gastroenterology and Hepatology, Emek Medical Center, Afula, Israel

2 Rappaport Faculty of Medicine, Technion-Israel Institute of Technology, Haifa, Israel

3 Department of Gastroenterology, Glasgow Royal Infirmary, Glasgow, UK

4 Sorbonne University, Endoscopic Unit, Saint Antoine Hospital Assistance Publique Hopitaux de Paris, Paris, France

5 Department of Surgery, Prince of Wales Hospital, The Chinese University of Hong Kong, Hong Kong SAR, China

6 Digestive Disease Services, University Clinic Hospital, University of Zaragoza, IIS Aragón (CIBERehd), Spain

7 Department of Gastroenterology, Odense University Hospital, Odense, Denmark

8 Department of Gastroenterology, Valduce Hospital, Como, Italy

9 Hepatogastroenterology Unit, Second Department of Internal Medicine - Propaedeutic, Medical School, National and Kapodistrian University of Athens, Attikon University General Hospital, Athens, Greece

10 Gastroenterology Department, Hospital da Senhora da Oliveira, Guimarães, Portugal

11 School of Medicine, University of Minho, Braga/ Guimarães, Portugal

12 ICVS/3B's-PT Government Associate Laboratory, Braga/Guimarães, Portugal

13 Center for Research in Health Technologies and Information Systems (CINTESIS), Faculty of Medicine, Porto, Portugal

14 Gastroenterology Department, Portuguese Oncology Institute of Porto, Portugal

15 Medizinische Klinik 3, Universitätsklinikum Augsburg, Augsburg, Germany.

16 Red Cross Hospital Beverwijk, Beverwijk, The Netherlands
17 Gastroenterological Surgery, University of Helsinki and Helsinki University Hospital, Helsinki, Finland

18 Gastroenterology Unit, Hospital Costa del Sol, Marbella, Spain

19 Gastroenterology Department, Vithas Xanit International Hospital, Benalmadena, Spain

20 Diagnostic Imaging and Nuclear Medicine Institute, Emek Medical Center, Afula, Israel

21 Department of Gastroenterology and Hepatology, Leiden University Medical Center, Leiden, The Netherlands

published online 10.2 .2021

\section{Bibliography}

Endoscopy 2021; 53: 300-332

DOI 10.1055/a-1369-5274

ISSN 0013-726X

(C) 2021. European Society of Gastrointestinal Endoscopy All rights reserved.

This article ist published by Thieme.

Georg Thieme Verlag KG, Rüdigerstraße 14,

70469 Stuttgart, Germany

$\circledast$ Supplementary material

Supplementary material is available under

https://doi.org/10.1055/a-1369-5274

Corresponding author

Ian M. Gralnek, MD MSHS, Rappaport Faculty of Medicine, Technion-Israel Institute of Technology, Institute of Gastroenterology and Hepatology, Emek Medical Center, Afula, Israel 18101

ian_gr@clalit.org.il 


\section{MAIN RECOMMENDATIONS}

1 ESGE recommends in patients with acute upper gastrointestinal hemorrhage (UGIH) the use of the GlasgowBlatchford Score (GBS) for pre-endoscopy risk stratification. Patients with GBS $\leq 1$ are at very low risk of rebleeding, mortality within 30 days, or needing hospital-based intervention and can be safely managed as outpatients with outpatient endoscopy.

Strong recommendation, moderate quality evidence.

2 ESGE recommends that in patients with acute UGIH who are taking low-dose aspirin as monotherapy for secondary cardiovascular prophylaxis, aspirin should not be interrupted. If for any reason it is interrupted, aspirin should be restarted as soon as possible, preferably within 3-5 days. Strong recommendation, moderate quality evidence.

3 ESGE recommends that following hemodynamic resuscitation, early ( $\leq 24$ hours) upper gastrointestinal (GI) endoscopy should be performed.

Strong recommendation, high quality evidence.

4 ESGE does not recommend urgent ( $\leq 12$ hours) upper GI endoscopy since as compared to early endoscopy, patient outcomes are not improved.

Strong recommendation, high quality evidence.

5 ESGE recommends for patients with actively bleeding ulcers (Fla, Flb), combination therapy using epinephrine injection plus a second hemostasis modality (contact thermal or mechanical therapy).

Strong recommendation, high quality evidence.

6 ESGE recommends for patients with an ulcer with a nonbleeding visible vessel (FIla), contact or noncontact thermal therapy, mechanical therapy, or injection of a sclerosing agent, each as monotherapy or in combination with epinephrine injection.

Strong recommendation, high quality evidence.
7 ESGE suggests that in patients with persistent bleeding refractory to standard hemostasis modalities, the use of a topical hemostatic spray/powder or cap-mounted clip should be considered.

Weak recommendation, low quality evidence.

8 ESGE recommends that for patients with clinical evidence of recurrent peptic ulcer hemorrhage, use of a cap-mounted clip should be considered. In the case of failure of this second attempt at endoscopic hemostasis, transcatheter angiographic embolization (TAE) should be considered. Surgery is indicated when TAE is not locally available or after failed TAE.

Strong recommendation, moderate quality evidence.

9 ESGE recommends high dose proton pump inhibitor (PPI) therapy for patients who receive endoscopic hemostasis and for patients with Fllb ulcer stigmata (adherent clot) not treated endoscopically.

(a) PPI therapy should be administered as an intravenous bolus followed by continuous infusion (e.g., $80 \mathrm{mg}$ then $8 \mathrm{mg} /$ hour) for 72 hours post endoscopy.

(b) High dose PPI therapies given as intravenous bolus dosing (twice-daily) or in oral formulation (twice-daily) can be considered as alternative regimens.

Strong recommendation, high quality evidence.

10 ESGE recommends that in patients who require ongoing anticoagulation therapy following acute NVUGIH (e.g., peptic ulcer hemorrhage), anticoagulation should be resumed as soon as the bleeding has been controlled, preferably within or soon after 7 days of the bleeding event, based on thromboembolic risk. The rapid onset of action of direct oral anticoagulants (DOACS), as compared to vitamin $\mathrm{K}$ antagonists (VKAs), must be considered in this context. Strong recommendation, low quality evidence.

\section{SOURCE AND SCOPE}

This Guideline is an official statement from the European Society of Gastrointestinal Endoscopy (ESGE). It is an update of the previously published 2015 ESGE Clinical Guideline addressing the role of gastrointestinal endoscopy in the diagnosis and management of acute nonvariceal upper gastrointestinal hemorrhage (NVUGIH). The evidence statements and recommendations specifically pertaining to endoscopic hemostasis therapies are limited to peptic ulcer hemorrhage. Endoscopic hemostasis therapy recommendations for nonulcer NVUGIH etiologies, can be found in the 2015 ESGE Guideline.

\section{Introduction}

The most common causes of acute upper gastrointestinal hemorrhage (UGIH) are nonvariceal. These include gastric and duodenal peptic ulcers, mucosal erosive disease of the esophagus/stomach/duodenum, malignancy, Mallory-Weiss syndrome, Dieulafoy lesion, "other" diagnosis, or no identifiable cause [1]. This ESGE Guideline focuses on the pre-endoscopic, endoscopic, and post-endoscopic management of patients presenting with acute nonvariceal upper gastrointestinal hemorrhage (NVUGIH), specifically peptic ulcer hemorrhage. 


\begin{tabular}{|c|c|c|c|}
\hline \multicolumn{4}{|c|}{ ABBREVIATIONS } \\
\hline APA & antiplatelet agent & NGT & nasogastric tube \\
\hline APC & argon plasma coagulation & NNT & number needed to treat \\
\hline ASA & American Society of Anesthesiologists & NVUGIH & nonvariceal upper gastrointestinal \\
\hline AUROC & area under receiver operating characteristic & & hemorrhage \\
\hline DAPT & dual antiplatelet therapy & OR & odds ratio \\
\hline \multirow[t]{3}{*}{ CHADS2 } & congestive heart failure, hypertension, age & OTS & over-the-scope \\
\hline & $\geq 75$ years, diabetes mellitus, and previous & PCC & prothrombin complex concentrate \\
\hline & stroke or transient ischemic attack [risk score] & $\mathrm{PCl}$ & percutaneous coronary intervention \\
\hline $\mathrm{Cl}$ & confidence interval & PICO & patients, interventions, controls, outcomes \\
\hline DOAC & direct oral anticoagulant & PNED & Progetto Nazionale Emorragia Digestive \\
\hline \multirow{2}{*}{ ESGE } & European Society of Gastrointestinal & PPI & proton pump inhibitor \\
\hline & Endoscopy & PUB & peptic ulcer bleeding \\
\hline FFP & fresh frozen plasma & RBC & red blood cell \\
\hline GBS & Glasgow-Blatchford Score & $\mathrm{RCT}$ & randomized controlled trial \\
\hline GI & gastrointestinal & RD & risk difference \\
\hline \multirow[t]{2}{*}{ GRADE } & Grading of Recommendations Assessment, & $\mathbf{R R}$ & relative risk or risk ratio \\
\hline & Development and Evaluation & TAE & transcatheter angiographic embolization \\
\hline HR & hazard ratio & TTS & through-the-scope \\
\hline ICU & intensive care unit & TXA & tranexamic acid \\
\hline INR & international normalized ratio & UGIH & upper gastrointestinal hemorrhage \\
\hline IRR & incident rate ratio & VKA & vitamin $\mathrm{K}$ antagonist \\
\hline NBVV & nonbleeding visible vessel & & \\
\hline
\end{tabular}

\section{Methods}

ESGE commissioned this Guideline (ESGE Guideline Committee chair, J.V.H.) and appointed a guideline leader (I.M.G.). The guideline leader established four task forces based on the statements of the previous 2015 Guideline [2], each with its own lea$\operatorname{der}$ (M.C., A.J.S., J.M., J.L.).

Key questions (Table $1 \mathrm{~s}$, see online-only in Supplementary material) were prepared by the coordinating team (I.M.G., M. C., A.S., J.M., J.L.) according to the PICO format (patients, interventions, controls, outcomes) and divided amongst the four task forces. Given this is an update of the 2015 ESGE Clinical Guideline on NVUGIH, each task force performed a structured systematic literature search using key words (Table2s) in English-language articles limited from January 1, 2014 to January 31, 2020, in Ovid MEDLINE, Embase, Google Scholar, and the Cochrane Database of Systematic Reviews. Additional topic-specific searches on timing of endoscopy and role of capmounted clips for hemostasis in peptic ulcer hemorrhage were conducted up to August 31, 2020. The hierarchy of studies included in this evidence-based guideline was, in decreasing order of evidence level, published systematic reviews/metaanalyses, randomized controlled trials (RCTs), prospective and retrospective observational studies, and case series. New evidence on each key question was summarized in evidence tables (Table 3s), using the Grading of Recommendations Assessment, Development and Evaluation (GRADE) system [3]. Grading of the evidence depends on the balance between the benefits and risk or burden of any health intervention. Further details on ESGE guideline development have been previously reported [4].
The results of the literature search and answers to PICO questions were presented to all guideline group members during two online face-to-face meetings conducted on June 27 and 28,2020 . Subsequently, drafts were made by each task force leader and distributed between the task force members for revision and online discussion. In September 2020, a draft prepared by I.M.G. and the four task force leaders was sent to all guideline group members. After agreement of all members was obtained, the manuscript was reviewed by two independent external reviewers. The manuscript was then sent for further comments to the 49 ESGE member societies and individual members. It was then submitted to the journal Endoscopy for publication. The final revised manuscript was agreed upon by all the authors. This ESGE Guideline was issued in 2021 and will be considered for update in 2025. Any interim updates will be noted on the ESGE website: http://www.esge.com/esge-guidelines.html.

\section{Evidence statements and Recommendations}

Evidence statements and Recommendations are grouped according to the different task force topics: pre-endoscopy management (task forces 1 and 2), intraendoscopy management (task force 3), and postendoscopy management (task force 4). Each statement is followed by the strength of evidence based on GRADE and the discussion of the evidence that occurred during the two 3-hour online face-to-face meetings. > Table 1 summarizes all recommendations in this updated guideline. 
- Table 1 Summary of Guideline statements and recommendations.

Pre-endoscopy management

Initial patient evaluation and hemodynamic resuscitation

$1 \quad$ ESGE recommends immediate assessment of hemodynamic status in patients who present with acute upper gastrointestinal hemorrhage (UGIH), with prompt intravascular volume replacement initially using crystalloid fluids if hemodynamic instability exists.

Strong recommendation, low quality evidence.

Red blood cell (RBC) transfusion strategy

2 ESGE recommends, in hemodynamically stable patients with acute UGIH and no history of cardiovascular disease, a restrictive RBC transfusion strategy with a hemoglobin threshold of $\leq 7 \mathrm{~g} / \mathrm{dL}$ prompting $R B C$ transfusion. A post-transfusion target hemoglobin concentration of $7-9 \mathrm{~g} / \mathrm{dL}$ is desired.

Strong recommendation, moderate quality evidence.

3 ESGE recommends in hemodynamically stable patients with acute UGIH and a history of acute or chronic cardiovascular disease, a more liberal RBC transfusion strategy with a hemoglobin threshold of $\leq 8 \mathrm{~g} / \mathrm{dL}$ prompting RBC transfusion. A post transfusion target hemoglobin concentration of $\geq 10 \mathrm{~g} / \mathrm{dL}$ is desired.

Strong recommendation, low quality evidence.

Patient risk stratification

$4 \quad$ ESGE recommends in patients with acute UGIH the use of the Glasgow-Blatchford Score (GBS) for pre-endoscopy risk stratification. Patients with $\mathrm{GBS} \leq 1$ are at very low risk of rebleeding, mortality within 30 days, or needing hospital-based intervention and can be safely managed as outpatients with outpatient endoscopy.

Strong recommendation, moderate quality evidence.

Management of antithrombotic agents (antiplatelet agents and anticoagulants)

5 ESGE recommends that in patients with acute UGIH who are taking low dose aspirin as monotherapy for primary cardiovascular prophylaxis, aspirin should be temporarily interrupted. Aspirin can be re-started after careful re-evaluation of its clinical indication.

Strong recommendation, low quality evidence.

$6 \quad$ ESGE recommends that in patients with acute UGIH who are taking low dose aspirin as monotherapy for secondary cardiovascular prophylaxis, aspirin should not be interrupted. If for any reason it is interrupted, aspirin should be re-started as soon as possible, preferably within 3-5 days.

Strong recommendation, moderate quality evidence.

7 ESGE recommends that in patients with acute UGIH who are taking dual antiplatelet therapy (DAPT) for secondary cardiovascular prophylaxis, aspirin should not be interrupted. The second antiplatelet agent should be interrupted, but re-started as soon as possible, preferably within 5 days. Cardiology consultation is suggested.

Strong recommendation, low quality evidence.

$8 \quad$ ESGE does not recommend routine platelet transfusion for patients with acute NVUGIH who are taking antiplatelet agents. Strong recommendation, low quality evidence.

$9 \quad$ ESGE does not recommend the use of tranexamic acid in patients with acute NVUGIH.

Strong recommendation, high quality evidence.

10 ESGE recommends that in patients with acute UGIH taking vitamin K antagonists (VKAs), that the anticoagulant be withheld. Strong recommendation, low quality evidence

11 ESGE recommends that in patients with acute UGIH taking vitamin K antagonists (VKAs) who have hemodynamic instability, low dose vitamin K supplemented with intravenous prothrombin complex concentrate (PCC), or fresh frozen plasma (FFP) if PCC is not available, should be administered. However, this should not delay endoscopy or if required, endoscopic hemostasis.

Strong recommendation, low quality evidence.

12 ESGE recommends that in patients with acute UGIH taking direct oral anticoagulants (DOAC), the anticoagulant should be withheld and endoscopy not delayed. In patients with severe ongoing bleeding, use of a DOAC reversal agent or intravenous PCC should be considered. Strong recommendation, low quality evidence.

Proton pump inhibitor (PPI) therapy

13 ESGE suggests that pre-endoscopy high dose intravenous proton pump inhibitor (PPI) therapy be considered in patients presenting with acute UGIH, to downstage endoscopic stigmata and thereby reduce the need for endoscopic therapy; however, this should not delay early endoscopy. Weak recommendation, high quality evidence. 
Somatostatin and somatostatin analogues

14 ESGE does not recommend the use of somatostatin, or its analogue octreotide, in patients with NVUGIH.

Strong recommendation, low quality evidence.

Nasogastric/orogastric tube aspiration and lavage

15 ESGE does not recommend the routine use of nasogastric or orogastric aspiration/lavage in patients presenting with acute UGIH. Strong recommendation, moderate quality evidence.

Endotracheal intubation

16 ESGE does not recommend routine prophylactic endotracheal intubation for airway protection prior to upper endoscopy in patients with acute UGIH.

Strong recommendation, high quality evidence.

17 ESGE recommends prophylactic endotracheal intubation for airway protection prior to upper endoscopy only in selected patients with acute UGIH (i. e., those with ongoing active hematemesis, agitation, or encephalopathy with inability to adequately control the airway).

Strong recommendation, low quality evidence.

Prokinetic medications

18 ESGE recommends pre-endoscopy administration of intravenous erythromycin in selected patients with clinically severe or ongoing active UGIH.

Strong recommendation, high quality evidence.

\section{Endoscopic management}

Timing of upper Gl endoscopy

$1 \quad$ ESGE recommends adopting the following definitions regarding the timing of upper GI endoscopy in acute UGIH relative to the time of patient presentation: urgent $\leq 12$ hours, early $\leq 24$ hours, and delayed $>24$ hours.

Strong recommendation, moderate quality evidence.

2 ESGE recommends that following hemodynamic resuscitation, early ( $\leq 24$ hours) upper Gl endoscopy should be performed. Strong recommendation, high quality evidence.

3 ESGE does not recommend urgent ( $\leq 12$ hours) upper Gl endoscopy since as compared to early endoscopy, patient outcomes are not improved.

Strong recommendation, high quality evidence.

$4 \quad$ ESGE does not recommend emergent ( $\leq 6$ hours) upper Gl endoscopy since this may be associated with worse patient outcomes. Strong recommendation, moderate quality evidence.

5 ESGE recommends that the use of antiplatelet agents, anticoagulants, or a predetermined international normalized ratio (INR) cutoff level, should not be used to define or guide the timing of upper Gl endoscopy in patients with acute UGIH.

Strong recommendation, low quality evidence.

On-call Gl endoscopy resources

6 ESGE recommends the availability of both an on-call GI endoscopist proficient in endoscopic hemostasis and on-call nursing staff with technical expertise in the use of endoscopic devices, to allow performance of endoscopy on a 24/7 basis.

Strong recommendation, low quality evidence.

Endoscopic diagnosis

7 ESGE recommends the Forrest (F) classification be used in all patients with peptic ulcer hemorrhage to differentiate low risk and high risk endoscopic stigmata.

Strong recommendation, high quality evidence.

$8 \quad$ ESGE recommends that peptic ulcers with spurting or oozing bleeding (Fla and Flb respectively) or with a nonbleeding visible vessel (Flla) receive endoscopic hemostasis because these lesions are at high risk for persistent bleeding or recurrent bleeding.

Strong recommendation, high quality evidence.

9 ESGE suggests that peptic ulcers with an adherent clot (FIlb) be considered for endoscopic clot removal. Once the clot is removed, any identified underlying active bleeding (Fla or Flb) or nonbleeding visible vessel (Flla) should receive endoscopic hemostasis.

Weak recommendation, moderate quality evidence.

10 ESGE does not recommend endoscopic hemostasis in patients with peptic ulcers having a flat pigmented spot (FIIc) or clean base (FIII), as these stigmata have a low risk of adverse outcomes. In selected clinical settings these patients may have expedited hospital discharge. Strong recommendation, moderate quality evidence.

11 ESGE does not recommend the routine use of Doppler endoscopic probe in the evaluation of endoscopic stigmata of peptic ulcer bleeding. Strong recommendation, low quality evidence. 
ESGE does not recommend the routine use of capsule endoscopy technology in the evaluation of acute UGIH. Strong recommendation, low quality evidence.

Endoscopic therapy for peptic ulcer hemorrhage

13 Fla, Flb (active bleeding)

(a) ESGE recommends for patients with actively bleeding ulcers (Fla, Flb), combination therapy using epinephrine injection plus a second hemostasis modality (contact thermal or mechanical therapy).

Strong recommendation, high quality evidence.

(b) ESGE suggests that in selected actively bleeding ulcers (Fla,Flb), specifically those $>2 \mathrm{~cm}$ in size, with a large visible vessel $>2 \mathrm{~mm}$, or located in a high-risk vascular area (e. g., gastroduodenal, left gastric arteries), or in excavated/fibrotic ulcers, endoscopic hemostasis using a cap-mounted clip should be considered as first-line therapy.

Weak recommendation, low quality evidence.

$14 \quad$ Flla (nonbleeding visible vessel)

ESGE recommends for patients with an ulcer with a nonbleeding visible vessel (FIla), contact or noncontact thermal therapy, mechanical therapy, or injection of a sclerosing agent, each as monotherapy or in combination with epinephrine injection.

Strong recommendation, high quality evidence.

15 ESGE does not recommend that epinephrine injection be used as endoscopic monotherapy. If used, it should be combined with a second endoscopic hemostasis modality.

Strong recommendation, high quality evidence.

16 ESGE recommends that persistent bleeding be defined as ongoing active bleeding refractory to standard hemostasis modalities. Strong recommendation, high quality evidence.

17 ESGE suggests that in patients with persistent bleeding refractory to standard hemostasis modalities, the use of a topical hemostatic spray/powder or cap-mounted clip should be considered.

Weak recommendation, low quality evidence.

18 ESGE recommends that in patients with persistent bleeding refractory to all modalities of endoscopic hemostasis, transcatheter angiographic embolization (TAE) should be considered. Surgery is indicated when TAE is not locally available or after failed TAE. Strong recommendation, moderate quality evidence.

19 ESGE suggests considering the use of hemostatic forceps as an alternative endoscopic hemostasis option in peptic ulcer hemorrhage. Weak recommendation, moderate quality evidence.

\section{Post-endoscopy management}

Proton pump inhibitor (PPI) therapy

$1 \quad$ ESGE recommends high dose PPI therapy for patients who receive endoscopic hemostasis and for patients with FIIb ulcer stigmata (adherent clot) not treated endoscopically.

(a) PPI therapy should be administered as an intravenous bolus followed by continuous infusion (e. g., $80 \mathrm{mg}$ then $8 \mathrm{mg} /$ hour) for 72 hours post endoscopy.

(b) High dose PPI therapies given as intravenous bolus dosing (twice-daily) or in oral formulation (twice-daily) can be considered as alternative regimens.

Strong recommendation, high quality evidence.

Second-look endoscopy

2 ESGE does not recommend routine second-look endoscopy as part of the management of NVUGIH. Strong recommendation, high quality evidence.

Management of recurrent bleeding

3 ESGE recommends that recurrent bleeding be defined as bleeding following initial successful endoscopic hemostasis. Strong recommendation, high quality evidence.

$4 \quad$ ESGE recommends that patients with clinical evidence of recurrent bleeding should receive repeat upper endoscopy with hemostasis if indicated.

Strong recommendation, high quality evidence.

5 ESGE recommends that in the case of failure of this second attempt at endoscopic hemostasis, transcatheter angiographic embolization (TAE) should be considered. Surgery is indicated when TAE is not locally available or after failed TAE.

Strong recommendation, high quality evidence. 
6 ESGE recommends that for patients with clinical evidence of recurrent peptic ulcer hemorrhage, use of a cap-mounted clip should be considered. In the case of failure of this second attempt at endoscopic hemostasis, transcatheter angiographic embolization (TAE) should be considered. Surgery is indicated when TAE is not locally available or after failed TAE. Strong recommendation, moderate quality evidence.

Helicobacter pylori

$7 \quad$ ESGE recommends, in patients with NVUGIH secondary to peptic ulcer, investigation for the presence of Helicobacter pylori in the acute setting (at index endoscopy) with initiation of appropriate antibiotic therapy when $\mathrm{H}$. pylori is detected. Strong recommendation, high quality evidence.

$8 \quad$ ESGE recommends re-testing for $H$. pylori in those patients with a negative test at index endoscopy. Strong recommendation, high quality evidence.

$9 \quad$ ESGE recommends documentation of successful H. pylori eradication. Strong recommendation, high quality evidence.

Dual antiplatelet therapy and PPI co-therapy

10 ESGE recommends that in patients who have had acute NVUGIH and require ongoing dual antiplatelet therapy (DAPT), PPI should be given as co-therapy.

Strong recommendation, moderate quality evidence.

Re-starting anticoagulation therapy (vitamin Kantagonists [VKAs], direct oral anticoagulants [DOACs])

11 ESGE recommends that in patients who require ongoing anticoagulation therapy following acute NVUGIH (e. g., peptic ulcer hemorrhage), anticoagulation should be resumed as soon as the bleeding has been controlled, preferably within or soon after 7 days of the bleeding event, based on thromboembolic risk. The rapid onset of action of direct oral anticoagulants (DOACS), as compared to vitamin K antagonists (VKAs), must be considered in this context. Strong recommendation, low quality evidence.

12 ESGE recommends PPIs for gastroduodenal prophylaxis in patients requiring ongoing anticoagulation and with a history of NVUGIH. Strong recommendation, low quality evidence.

\section{Pre-endoscopy management}

\section{Initial patient evaluation and hemodynamic resuscitation}

\section{RECOMMENDATION}

ESGE recommends immediate assessment of hemodynamic status in patients who present with acute upper gastrointestinal hemorrhage (UGIH), with prompt intravascular volume replacement initially using crystalloid fluids if hemodynamic instability exists.

Strong recommendation, low quality evidence.

The goals of hemodynamic resuscitation are to correct intravascular hypovolemia, restore adequate tissue perfusion, and prevent multiorgan failure. Early intensive hemodynamic resuscitation of patients with acute UGIH has been shown to significantly decrease mortality [5]. However, uncertainty remains regarding the optimal rate of fluid resuscitation (aggressive vs. restrictive) [6-9]. A small RCT, including 51 participants presenting with acute UGIH and hemorrhagic shock, suggested that as compared to a conventional fluid resuscitation strategy, a restrictive fluid resuscitation regimen combined with an inotropic pharmacologic agent (dopamine hydrochloride) led to fewer adverse events [6]. A meta-analysis of 11 studies, including 3 studies specifically on $\mathrm{UGIH}$, reported significant reductions in mortality (risk ratio [RR] 0.67, $95 \% \mathrm{Cl} 0.56-0.81$; $P<0.001$ ), postoperative complications (multiorgan dysfunction syndrome, RR $0.37,95 \% \mathrm{Cl} 0.21-0.66, P<0.001$, and acute respiratory distress syndrome, RR $0.35,95 \% \mathrm{Cl} 0.21-$ 0.6 ; $P<0.001)$ in those patients receiving limited fluid resuscitation [8]. However, most of the patients in this meta-analysis suffered from trauma, and it is unclear whether the results can be extrapolated to patients with acute UGIH.

Moreover, there is ongoing uncertainty regarding the ideal crystalloid fluid type to be used in hemodynamic resuscitation for acute UGIH, either saline $0.9 \%$ sodium chloride or balanced crystalloids [10-12]. The selection of fluid type in critically ill patients requires careful consideration, based on safety, effects on patient outcomes, and costs. In both a large RCT and a metaanalysis of critically ill patients (most without UGIH), as compared to saline, use of a balanced crystalloid solution (e.g., lactated Ringer's solution) was shown to reduce both mortality and major adverse renal events $[11,12]$. However, there remains a lack of evidence for the subgroup of patients presenting with acute UGIH. 


\section{Red blood cell (RBC) transfusion strategy}

\section{RECOMMENDATION}

ESGE recommends, in hemodynamically stable patients with acute UGIH and no history of cardiovascular disease, a restrictive red blood cell (RBC) transfusion strategy with a hemoglobin threshold of $\leq 7 \mathrm{~g} / \mathrm{dL}$ prompting RBC transfusion. A post-transfusion target hemoglobin concentration of $7-9 \mathrm{~g} / \mathrm{dL}$ is desired.

Strong recommendation, moderate quality evidence.

\section{RECOMMENDATION}

ESGE recommends, in hemodynamically stable patients with acute UGIH and a history of acute or chronic cardiovascular disease, a more liberal RBC transfusion strategy with a hemoglobin threshold of $\leq 8 \mathrm{~g} / \mathrm{dL}$ prompting RBC transfusion. A post-transfusion target hemoglobin concentration of $\geq 10 \mathrm{~g} / \mathrm{dL}$ is desired.

Strong recommendation, low quality evidence.

A restrictive red blood cell ( $R B C$ ) transfusion strategy is considered standard of care in non-massive, acute UGIH [13-15]. A meta-analysis of five RCTs comprising 1965 patients with acute UGIH reported that, as compared to a liberal RBC transfusion strategy, a restrictive RBC transfusion strategy was associated with significantly lower mortality (RR $0.65,95 \% \mathrm{Cl} 0.44-0.97$ ) and reduced rebleeding ( $R R 0.58,95 \% \mathrm{Cl} 0.40-0.84)$ [16]. This was true for patients with both variceal or nonvariceal bleeding. However, the hemoglobin thresholds that prompted RBC transfusion differed between RCTs and most of the data used in the meta-analysis came from two large RCTs, which could affect generalizability $[13,14]$.

A meta-analysis of 31 RCTs comprising 12587 anemic patients with a variety of underlying comorbidities found that a restrictive $\mathrm{RBC}$ transfusion strategy did not adversely affect patient outcomes. In-hospital mortality was lower with a restrictive strategy, but 30-day mortality was not significantly different (RR 0.97, 95\%Cl 0.81-1.16) [17]. The most common hemoglobin thresholds used to prompt RBC transfusion were $\leq 7 \mathrm{~g} / \mathrm{dL}$ or $\leq 8 \mathrm{~g} / \mathrm{dL}$ for the restrictive RBC transfusion strategy and $\leq 9 \mathrm{~g} / \mathrm{dL}$ or $\leq 10 \mathrm{~g} / \mathrm{dL}$ for the liberal transfusion strategy. Despite limited data, this meta-analysis concluded that a restrictive RBC transfusion strategy appeared to be safe in patients with underlying cardiovascular disease. However, there were no available data for patients with acute coronary syndrome.

In a separate meta-analysis examining the effects of a restrictive versus liberal RBC transfusion strategy on outcomes in patients with cardiovascular disease not undergoing cardiac surgery (11 RCTs including 3033 patients with cardiovascular disease), Docherty et al. found that it may not be safe to use a hemoglobin threshold of $<8 \mathrm{~g} / \mathrm{dL}$ to prompt RBC transfusion in patients with ongoing acute coronary syndrome or chronic cardiovascular disease [18]. The authors reported that the risk of acute coronary syndrome in patients managed with a restrictive RBC transfusion strategy was significantly increased (RR $1.78,95 \% \mathrm{Cl} 1.18-2.70, P=0.01)$. The authors concluded that until adequately powered, high quality RCTs become available for patients with cardiovascular disease, a more liberal hemoglobin threshold $(>8 \mathrm{~g} / \mathrm{dL}$ ) to prompt RBC transfusion should be used for patients with both acute or chronic cardiovascular disease.

\section{Patient risk stratification}

\section{RECOMMENDATION}

ESGE recommends, in patients with acute UGIH, the use of the Glasgow-Blatchford Score (GBS) for pre-endoscopy risk stratification. Patients with $G B S \leq 1$ are at very low risk of rebleeding, mortality within 30 days, or needing hospital-based intervention and can be safely managed as outpatients with outpatient endoscopy.

Strong recommendation, moderate quality evidence.

Three risk stratification scores have been primarily studied in patients presenting with acute UGIH: the Glasgow-Blatchford Score (GBS), the pre-endoscopy Rockall Score, and the AIMS65 [19-21]. Risk stratification of patients presenting with acute UGIH can assist the triage of patients to in-hospital versus outof-hospital management. Our updated systematic literature search identified several recent studies that provide additional evidence supporting pre-endoscopy risk stratification and identification of low risk patients. A retrospective study of 2305 consecutive patients admitted for suspected UGIH demonstrated that a GBS $\leq 1$ identified a significantly higher proportion of true low risk patients compared with a GBS $=0(24.4 \%$ vs. $13.6 \%, P<0.001$ ) [22]. A systematic review assessed the predictive value of pre-endoscopy risk scores for 30-day serious adverse events (the composite outcome included 30-day mortality, recurrent bleeding, and need for intervention) [23]. Overall, the predictive value of the GBS was superior (sensitivity and specificity of 0.98 and 0.16 , respectively, as compared to 0.93 and 0.24 , respectively, for the pre-endoscopy Rockall score, and 0.79 and 0.61 , respectively, for the AIMS65). In a prospective, international cohort study including 3012 patients, Stanley et al. evaluated the accuracy of the Rockall preendoscopy and complete scores, and the AIMS65, GBS, and Progetto Nazionale Emorragia Digestive (PNED) [24]. The GBS was reported to have the highest accuracy (AUROC 0.86) for predicting need for hospital-based intervention (RBC transfusion, endoscopic treatment, arterial embolization, surgery) or death. Moreover, a GBS $\leq 1$ was the optimal threshold to predict patient survival without need for hospital-based intervention, with a sensitivity of $98.6 \%$ and specificity of $34.6 \%$. However, none of the evaluated risk scores were able to predict other outcomes with acceptable ability (AUROC $\leq 0.80$ ).

The sensitivity of a risk stratification score (e.g., detecting patients at high risk) is important so as not to incorrectly classify high risk patients as low risk when deciding on early hospital discharge. In contrast, risk score specificity is less crucial, since 
low specificity results in more low risk patients being admitted to hospital, but not in high risk patients being prematurely discharged. Moreover, the use of a validated risk stratification score (such as the GBS) with early discharge of low risk patients can reduce the need for endoscopy services, hospital admission, and resource utilization, without increasing patient risk. Two prospective studies found that implementation of GBS $=0$ as a standard for non-admission was associated with a positive clinical effect in terms of reduced rates of hospital admission (15\% of all acute UGIH patients), shorter length of hospital stay (6 vs. 19 hours), and reduced resource utilization among the low risk patients $[25,26]$. It should be noted that when the GBS is used to identify very low risk patients, discharged patients should be informed of the limited risk of recurrent bleeding and should be advised to maintain contact with the discharging hospital.

\section{Pre-endoscopy management of antithrombotic agents (antiplatelet agents and anticoagulants)}

\section{RECOMMENDATION}

ESGE recommends that in patients with acute UGIH who are taking low dose aspirin as monotherapy for primary cardiovascular prophylaxis, aspirin should be temporarily interrupted. Aspirin can be restarted after careful re-evaluation of its clinical indication.

Strong recommendation, low quality evidence.

\section{RECOMMENDATION}

ESGE recommends that in patients with acute UGIH who are taking low dose aspirin as monotherapy for secondary cardiovascular prophylaxis, aspirin should not be interrupted. If for any reason it is interrupted, aspirin should be restarted as soon as possible, preferably within 3-5 days.

Strong recommendation, moderate quality evidence.

\section{RECOMMENDATION}

ESGE recommends that in patients with acute UGIH who are taking dual antiplatelet therapy (DAPT) for secondary cardiovascular prophylaxis, aspirin should not be interrupted. The second antiplatelet agent should be interrupted, but restarted as soon as possible, preferably within 5 days. Cardiology consultation is suggested.

Strong recommendation, low quality evidence.

Patients with NVUGIH (e.g., peptic ulcer hemorrhage) who take antiplatelet agents face a serious clinical challenge since the risk of maintaining the antiplatelet agent to avoid thrombotic events must be balanced against the risk of persistent or recurrent bleeding. Both events are associated with increased mortality. Thus, it is important to know whether the indication for antiplatelet therapy is for primary or secondary cardiovascular prophylaxis. Primary prophylaxis is defined as use of antiplatelet agents by individuals who are free of, but at potential risk of developing cardiovascular disease. Secondary prophylaxis is the use of antiplatelet agents to prevent a second event in individuals who have had a myocardial infarction or certain types of cerebrovascular event. The evidence here however is limited and mostly restricted to low dose aspirin monotherapy. In the only published RCT, 156 recipients of low dose aspirin for secondary cardiovascular prophylaxis who had peptic ulcer bleeding with high risk endoscopic stigmata were randomized after endoscopic therapy to receive continuous aspirin or placebo [27]. At 8-week follow-up, all-cause mortality was significantly lower in the patients randomized to aspirin than in those receiving placebo ( $1.3 \%$ vs. $12.9 \%$; i. e., a difference of 11.6 percentage points, $95 \% \mathrm{Cl} 3.7-19.5$ percentage points; hazard ratio [HR] 0.20), with the difference being attributable to cardiovascular, cerebrovascular, or gastrointestinal complications. In a retrospective analysis of 118 low dose aspirin users who had been treated for peptic ulcer bleeding and who were followed up for a median of 2 years, 47 (40\%) patients stopped their aspirin [28]. Those who discontinued aspirin and those who continued aspirin had similar mortality rates (31\%). However, in the subgroup of patients with cardiovascular comorbidities, those who discontinued aspirin had an almost fourfold increase in the risk of death or an acute cardiovascular event $(P<0.01)$.

Three more recent observational studies reported similar results. One study reported on 544 patients with peptic ulcer bleeding, of whom 74 (13.6\%) were taking antithrombotic agents [29]. The HR for a thrombotic event when antithrombotic agents were discontinued was 10.9 (95\% Cl 1.3-89.7). No significant differences in recurrent bleeding events were observed between the two groups. A similar conclusion was reported in another retrospective cohort study [30]. Using Cox regression analysis, the investigators showed that the HR for recurrent bleeding was $2.98(95 \% \mathrm{Cl} 0.67-8.36)$ in patients who continued their antithrombotic agent(s) (85.5\% aspirin). However, the HR for death or acute cardiovascular disease in those who stopped taking antithrombotic agents was $5.21(95 \% \mathrm{Cl}$ 1.03-26.3). Lastly, Siau et al. evaluated outcomes in 118 patients with acute upper GI bleeding who had their antithrombotic therapy stopped at hospital discharge [31]. These authors reported that cessation of antithrombotic therapy was associated with increased mortality ( $\mathrm{HR} 3.3,95 \% \mathrm{Cl} 1.1-10.3)$, increased thrombotic events (HR 5.8, $95 \% \mathrm{Cl} 1.3-26.4$ ), and overall increased adverse events (HR 3.0, 95\%Cl 1.3-6.7). However, there was no significant increase in post-hospital discharge bleeding rates. These observational studies appear to concur with the only available RCT on this topic [27].

The optimal timing for the resumption of aspirin and/or other antiplatelet agents in the setting of acute NVUGIH (e.g., peptic ulcer hemorrhage) has not been adequately studied. A meta-analysis reported that the time interval to develop acute coronary syndrome after antithrombotic discontinuation is estimated to be within 1 week, and to be within 2 weeks for a cerebrovascular event [32]. In the updated Asia-Pacific working group consensus on nonvariceal upper gastrointestinal 
bleeding, it was recommended that in patients with peptic ulcer hemorrhage, antithrombotic agents could be restarted the same day or not be interrupted at all if endoscopy demonstrates a Forrest III (clean base) ulcer [33]. A recent retrospective cohort study, including $871 \mathrm{Gl}$ bleeding patients, of whom $25 \%$ had peptic ulcer hemorrhage and all of whom were taking antithrombotic medications (52.5\% antiplatelet agents), showed that at long-term follow-up (mean 24.9 months), resumption of either antiplatelet or anticoagulant therapy was associated with a higher risk of rebleeding, but a lower risk of an ischemic event or death [34]. Moreover, the investigators reported that when compared to late resumption of antithrombotic therapy, early resumption ( $\leq 7$ days) following the bleeding episode showed no difference in mortality, a lower rate of ischemic events (13.6\% vs. $20.4 \%$ ), yet a significantly higher rate of $\mathrm{Gl}$ rebleeding ( $30.6 \%$ vs. $23.1 \%$; $P=0.04$ ).

After 5 days of aspirin interruption, $50 \%$ of circulating platelets are new and therefore able to produce thromboxane which plays a key role in thrombotic events [35]. Therefore, aspirin can be temporarily interrupted and resumed within a 5-day window in patients considered at high risk for recurrent bleeding. Overall, there is good evidence to maintain, or at least to only temporarily interrupt and then quickly resume aspirin therapy after aspirin interruption in patients with known cardiovascular disease who develop peptic ulcer hemorrhage.

To date, no studies have specifically investigated outcomes of the interruption and/or timing of resumption of non-aspirin antiplatelet agents in patients with peptic ulcer hemorrhage. Moreover, the data that are available are limited to the use of aspirin for secondary cardiovascular prophylaxis. Therefore, recommendations to withhold aspirin that has been prescribed for primary cardiovascular prophylaxis in patients who develop peptic ulcer hemorrhage is based solely on clinical judgment. In such patients, the risk of persistent or recurrent bleeding should outweigh the risk of a cardiovascular event. However, in a recent study of 95 patients taking low dose aspirin for primary cardiovascular prevention who developed peptic ulcer hemorrhage, 18 (18.9\%) subsequently had a cardiovascular event during follow-up. This suggests that the actual cardiovascular risk and aspirin indication for these patients should be more adequately assessed before interrupting aspirin for longer periods of time [34].

No studies have evaluated the best management strategy for patients taking dual antiplatelet therapy (DAPT) who develop peptic ulcer hemorrhage. In general, patients taking DAPT have in the recent past undergone a percutaneous coronary intervention $(\mathrm{PCl})$ with stent placement and are at high risk of stent thrombosis if antiplatelet agents are interrupted [36]. Therefore, in patients with a recent $\mathrm{PCl}$ and stent placement and NVUGIH, a cardiologist should be consulted and maintenance of both antiplatelet agents be considered if the risk of rebleeding is thought to be low. $>$ Fig. $\mathbf{1}$ a, b outlines the management of antiplatelet therapy in patients with acute NVUGIH.

\section{RECOMMENDATION}

ESGE does not recommend routine platelet transfusion for patients with acute NVUGIH who are taking antiplatelet agents.

Strong recommendation, low quality evidence.

\section{RECOMMENDATION}

ESGE does not recommend the use of tranexamic acid in patients with acute NVUGIH.

Strong recommendation, high quality evidence.

There is no high quality evidence supporting the benefit of routine platelet transfusion in patients who have acute UGIH while taking antiplatelet agents. Moreover, endoscopic hemostasis appears safe in patients with thrombocytopenia [37]. Zakko et al. reported that platelet transfusion in patients with Gl bleeding taking antiplatelet medication(s), and in the absence of thrombocytopenia, did not reduce rebleeding, but was associated with higher mortality [38]. However, it would appear reasonable to consider platelet transfusion in patients taking antiplatelet medication(s) and with thrombocytopenia who have severe bleeding.

Several small studies and meta-analyses [39-42] have suggested benefit from use of tranexamic acid (TXA) in Gl bleeding. However, a recent international multicenter RCT (the HALT-IT study), comparing TXA versus placebo in acute GI bleeding, reported no mortality benefit from TXA. Mortality, defined as death due to bleeding within 5 days of randomization, was $4 \%$ (222 patients) in the TXA group and $4 \%(226)$ in the placebo group (RR $0.99,95 \% \mathrm{Cl} 0.82-1.18$ ). Moreover TXA was associated with a higher number of venous thromboembolic events (48 [0.8\%] vs. 26 [0.4\%]; RR 1.85, 95\%Cl 1.15-2.98) [43].

RECOMMENDATION

ESGE recommends that, in patients with acute UGIH taking vitamin $\mathrm{K}$ antagonists (VKAs) the anticoagulant be withheld.

Strong recommendation, low quality evidence. 


\section{RECOMMENDATION}

ESGE recommends that, in patients with acute UGIH taking vitamin $\mathrm{K}$ antagonists (VKAs) who have hemodynamic instability, low dose vitamin $\mathrm{K}$ supplemented with intravenous prothrombin complex concentrate (PCC), or fresh frozen plasma (FFP) if PCC is not available, should be administered. However, this should not delay endoscopy or, if required, endoscopic hemostasis.

Strong recommendation, low quality evidence.

\section{RECOMMENDATION}

ESGE recommends that, in patients with acute UGIH taking direct oral anticoagulants (DOACs), the anticoagulant should be withheld and endoscopy not delayed. In patients with severe ongoing bleeding, use of a DOAC reversal agent or intravenous PCC should be considered. Strong recommendation, low quality evidence.

The management of patients taking anticoagulants (VKAs, DOACs) who develop acute UGIH (e.g., peptic ulcer hemorrhage) is clinically challenging since anticoagulant management must be addressed both prior to and following upper endoscopy [44]. Unfortunately, no studies have specifically addressed the optimal timing of endoscopy in patients receiving anticoagulants. Furthermore, since the pharmacokinetics and pharmacodynamic profiles of VKAs and DOACs are different, management is different. DOACs (factor Xa and thrombin inhibitors) have a rapid onset of action and a much shorter half-life than VKA, and routine tests for anticoagulant activity are lacking [45].

The anticoagulant effect of VKA is measured using the international normalized ratio (INR). Studies have shown that endoscopy outcomes in VKA-anticoagulated patients were similar in patients with normal INR compared with those with elevated INR at hospital admission, or in those where INR was corrected to a value $<2.5$ prior to endoscopy [44, 46-48]. More recent observational studies provide additional supporting evidence. Nagata et al. reported that in patients with acute upper (47\%) or lower Gl bleeding, early endoscopy (within 24 hours) in anticoagulant users $(n=157)$ was not associated with an increased risk of rebleeding ( $13.4 \%$ vs. $15.9 \%, P=0.52)$ or thromboembolic events ( $5.7 \%$ vs. $3.2 \%, P=0.68$ ) when compared to matched controls not taking anticoagulants [49]. An INR $>2.5$ was seen in $22.9 \%$ of the anticoagulant users at the time of endoscopy. However rapid INR correction was associated with an increased risk of thromboembolism, as suggested in other studies $[50,51]$. Another small study also suggested that the INR level did not affect rebleeding or endoscopy outcomes [52]. However, Peloquin et al. reported that in 134 patients with $\mathrm{Gl}$ bleeding and a supratherapeutic INR of $\geq 3.5$, therapeutic endoscopic intervention was less likely to be effective as the INR increased [53].
Reversal of the anticoagulant effect of VKAs in patients with acute UGIH can be achieved with low dose vitamin K, however, this takes time since the INR only starts to decrease within 2-4 hours and normalizes within 24 hours. Moreover, the anticoagulant reversal effect of vitamin $\mathrm{K}$ persists as compared to prothrombin complex concentrate (PCC) or fresh frozen plasma (FFP) [54]. Sin et al. reported that four-factor PCC appears to be associated with a significant thromboembolic risk; however it remains a useful agent for warfarin reversal [55]. That same study also suggested that in patients requiring reversal of warfarin anticoagulation, lack of concomitant vitamin $\mathrm{K}$ may contribute to "INR rebound," therefore concomitant low dose vitamin $\mathrm{K}$ may be appropriate in this situation. However, given the limited data, caution must be exercised when giving vitamin $\mathrm{K}$ since its persisting effect can impede re-coagulation efforts. Limitations of FFP include the requirement for a higher volume load to achieve a reversal effect, slower onset of action compared with PCC, and requirement for blood group typing. In addition, recent evidence suggests that use of FFP is associated with increased mortality in patients undergoing endoscopy for NVUGIH [56-58]. Three- or four-factor PCC or FFP can be used when the reversal of anticoagulation is urgent because of patient hemodynamic instability or life-threatening massive bleeding, irrespective of INR values. Recombinant factor VIIa is currently not recommended because of its high cost and higher risk of thromboembolism [59].

Patients who develop acute UGIH while taking DOACs must follow a similar protocol of early endoscopy and reversal of anticoagulation in cases of hemodynamic instability or lifethreatening bleeding. However, there are particular considerations because of DOAC's specific pharmacodynamics and the availability of antidotes which rapidly block its anticoagulation effects. It is important to know the time of the last DOAC dose, since most DOACs have an 8-12-hour half-life and their effect usually disappears within 24 hours. Hemodialysis is effective to remove dabigatran from plasma and can help to prevent rebleeding [60]. PCC has also been shown to be effective for reversal of anticoagulation in patients with acute UGIH who are taking DOACs $[61,62]$. However, the best potential therapeutic options rely on the availability of DOAC reversal agents that should be used in cases of life-threatening acute UGIH. The risk of thromboembolism with use of reversal agents is a concern, but very few data are available [63-67]. Idarucizumab is a specific antidote for dabigatran and works effectively within minutes. Thromboembolism and rebound effects have been reported in $6.8 \%$ and $23 \%$ of patients, respectively [63]. Other DOAC antidotes are being investigated but are not yet on the market [66, 67].

-Fig. 2 outlines management of anticoagulant therapy in patients with acute NVUGIH. 
Low dose aspirin used for primary prophylaxis

(a) Continue to withhold low dose aspirin

(b) Resume low dose aspirin after careful re-evaluation of its clinical indication
APA* used for secondary prophylaxis (known cardiovascular disease)

1 Patient on low dose aspirin alone

(a) Continue low dose aspirin without interruption

(b) If aspirin has been interrupted, resume within 3-5 days

(c) Second-look endoscopy should be at the discretion of the endoscopist, prior to restarting aspirin

2 Patient on dual antiplatelet therapy (DAPT)

(a) Continue low dose aspirin without interruption

(b) The second APA should be restarted as soon as possible, preferably within 5 days.

Cardiology consultation regarding timing of restarting second APA is suggested

(c) Second-look endoscopy should be at the discretion of the endoscopist, prior to restarting second APA

\section{Acute UGIH in a patient taking APA(s)}

UGI endoscopy demonstrates nonvariceal source of hemorrhage, e.g. peptic ulcer

Low risk endoscopic stigmata diagnosed

(FIlc, FIII - flat pigmented spot, clean-base ulcer)

Low dose aspirin used for primary prophylaxis

(a) Continue to withhold low dose aspirin

(b) Resume low dose aspirin after careful re-evaluation of its clinical indication
APA* used for secondary prophylaxis (known cardiovascular disease)

1 Patient on low dose aspirin alone

(a) Continue low dose aspirin without interruption

2 Patient on dual antiplatelet therapy (DAPT)

(a) Continue DAPT without interruption

b

- Fig. 1 Management of antiplatelet therapy in patients with acute nonvariceal upper gastrointestinal hemorrhage (NVUGIH) with a high risk, and $\mathbf{b}$ low risk stigmata, diagnosed at endoscopy. ${ }^{*}$ In patients using a nonaspirin antiplatelet agent (APA) as monotherapy (e. g. thienopyridine alone), low dose aspirin may be substituted for an interval period provided there is no contraindication or allergy to aspirin. Cardiology consultation is suggested for further APA recommendations. UGIH, upper gastrointestinal hemorrhage. 
Acute UGIH in patient taking anticoagulation (e.g., VKA, DOAC)

1 Withhold anticoagulant at time of patient presentation

2 In patients taking VKA and with hemodynamic instability, low dose vitamin K supplemented with intravenous PCC, or FFP if PCC not available, should be administered

3 In patients taking DOAC and with severe ongoing bleeding, use of a DOAC reversal agent or intravenous PCC should be considered

4 Upper Gl endoscopy and if required, endoscopic hemostasis, should not be delayed

Upper Gl endoscopy demonstrates nonvariceal source of hemorrhage

1 Anticoagulation should be resumed as soon as the bleeding has been controlled, preferably within or soon after 7 days of the bleeding event based on thromboembolic risk

2 Rapid onset of action of DOAC, as compared to VKA, must be considered in this context

3 Use of validated scores that estimate thrombotic risk (e.g., CHA2DS2-VASc) and bleeding risk (e.g., HAS-BLED) can be used to help guide clinical decision making

- Fig. 2 Management of anticoagulants in acute nonvariceal upper gastrointestinal hemorrhage (NVUGIH) before and after upper GI endoscopy. UGIH, upper gastrointestinal hemorrhage; VKA, vitamin $\mathrm{K}$ antagonist; DOAC, direct oral anticoagulant; PCC, prothrombin complex concentrate; FFP, fresh frozen plasma; $\mathrm{Gl}$, gastrointestinal.

\section{Pre-endoscopy proton pump inhibitor (PPI) therapy}

\section{RECOMMENDATION \\ ESGE suggests that pre-endoscopy high dose intravenous proton pump inhibitor (PPI) therapy be considered in pa- tients presenting with acute UGIH, to downstage endo- scopic stigmata and thereby reduce the need for endo- scopic therapy; however, this should not delay early endoscopy. \\ Weak recommendation, high quality evidence.}

In the systematic literature search (from January 2014 to January 2020) for this updated NVUGIH guideline, we were unable to identify any systematic reviews, meta-analyses, RCTs, or observational studies evaluating pre-endoscopy PPI administration in patients presenting with acute UGIH. Although preendoscopy PPI therapy significantly reduces the prevalence of high risk endoscopic stigmata in peptic ulcer hemorrhage at the time of index endoscopy, and thereby reduces the need for endoscopic hemostasis, PPIs provide no significant impact on patient outcomes, including recurrent hemorrhage, need for surgery, or mortality [68]. In the 2015 ESGE NVUGIH guideline, initiation of high dose intravenous PPI was recommended for patients presenting with acute UGIH awaiting upper endoscopy, without delaying early endoscopy [1]. This was a strong recommendation based upon high quality evidence. However, the lack of a significant impact of pre-endoscopy PPI therapy on clinically relevant patient outcomes in acute NVUGIH has recently led to revised recommendations from several international evidence-based guideline bodies. In 2018, the Asia-Pacific working group consensus revised their earlier support for routine pre-endoscopy intravenous PPI administration in acute $\mathrm{UGIH}$ [33]. Since there is no proven impact on patient outcomes and costs are increased, the working group members voted to reject the indiscriminate use of pre-endoscopy intravenous PPIs in patients presenting in a stable condition with symptoms suggestive of acute UGIH. However, the working group noted that when endoscopy facilities or expertise in acute UGIH are not available within 24 hours, the downgrading of stigmata of recent hemorrhage and reducing the need for urgent endoscopy by use of intravenous PPIs could be justified. In 2019, the International Consensus Group on NVUGIH recommended that "pre-endoscopic PPI therapy may be considered to downstage the endoscopic lesion and decrease the need for endoscopic intervention but should not delay endoscopy" [15]. This was the same as their earlier recommendation in 2010 [69]. Lastly, the recently published United Kingdom consensus care bundle for early clinical management of acute UGIH did not recommend use of PPI prior to endoscopy [70].

Considering the available evidence, ESGE now "suggests" that pre-endoscopy, high dose intravenous PPI "be considered" in patients presenting with acute UGIH. This change is reflective of the lack of high level evidence for the impact of preendoscopy PPI on clinically relevant patient outcomes and remains consistent with other recent NVUGIH guideline recommendations.

\section{Somatostatin and somatostatin analogues}

\section{RECOMMENDATION}

ESGE does not recommend the use of somatostatin, or its analogue octreotide, in patients with NVUGIH.

Strong recommendation, low quality evidence.

Somatostatin, and its analogue octreotide, inhibit both acid and pepsin secretion while also reducing gastroduodenal mucosal blood flow [71]. However, they are not recommended in NVUGIH (e.g., peptic ulcer bleeding), either before endoscopy or as an adjunctive therapy following endoscopy, since published data show little or no benefit. A recently published retrospective cohort study including 180 patients with acute NVUGIH continues to show no significant differences in outcomes between patients receiving combination therapy (PPI plus octreotide infusion) and those receiving PPI alone (hospital 
and intensive care unit [ICU] median length of stay, respectively, 6.1 vs. 4.9 days, $P=0.25$, and 2.3 vs. 1.9 days, $P=0.24$; rebleeding $9 \%$ vs. $12 \%, P=0.63$; RBC units transfused 3 vs. 2 units, $P=0.43$; and mortality $6.7 \%$ vs. $5.6 \%, P=1.00$ ) [72].

\section{Nasogastric/orogastric tube aspiration and lavage}

\section{RECOMMENDATION}

ESGE does not recommend the routine use of nasogastric or orogastric aspiration/lavage in patients presenting with acute UGIH.

Strong recommendation, moderate quality evidence.

A recent retrospective study and a review both concluded that nasogastric tube (NGT) aspiration does not differentiate upper from lower Gl bleeding in patients with melena [73, 74]. Moreover, a randomized, single-blind, noninferiority study comparing NGT placement (with aspiration and lavage) to no NGT placement ( $n=140$ in each arm), failed to show that NGT aspiration could accurately predict the presence of a high risk lesion requiring endoscopic therapy (39\% vs. $38 \%$, respectively) [75]. In addition, adverse events (pain, nasal bleeding, or failure of NGT placement) occurred in $34 \%$ and there were no observed differences in rebleeding rates or mortality.

\section{Endotracheal intubation}

\section{RECOMMENDATION}

ESGE does not recommend routine prophylactic endotracheal intubation for airway protection prior to upper endoscopy in patients with acute UGIH.

Strong recommendation, high quality evidence.

\section{RECOMMENDATION}

ESGE recommends prophylactic endotracheal intubation for airway protection prior to upper endoscopy only in selected patients with acute UGIH (i.e., those with ongoing active hematemesis, agitation, or encephalopathy with inability to adequately control their airway).

Strong recommendation, low quality evidence.

It has been posited that prophylactic endotracheal intubation prior to upper endoscopy in unselected patients with acute UGIH could protect the patient's airway from potential aspiration of gastric contents and prevent cardiorespiratory adverse events. However, three recent systematic reviews/meta-analyses and a small retrospective case series show that prophylactic endotracheal intubation before upper endoscopy in patients with acute UGIH may be associated with a higher risk of aspiration and pneumonia, longer hospital stays, and potentially higher mortality [76-79]. In a meta-analysis by Almashhrawi et al., the authors reported that in patients with acute UGIH who received prophylactic endotracheal intubation prior to upper endoscopy, pneumonia within 48 hours was identified in 20 of 134 patients (14.9\%) as compared with 5 of 95 patients (5.3\%) not prophylactically intubated ( $P=0.02$, OR 3.13) [78]. Despite observed trends, no significant differences were found for aspiration $(P=0.11)$ or mortality $(P=0.18)$. Alshamsi et al., in their meta-analysis including 10 observational studies $(n=$ 6068 patients), reported that prophylactic endotracheal intubation was associated with a significant increase in aspiration (OR 3.85, 95\%Cl 1.46-10.25; $P=0.01$ ), pneumonia (OR 4.17, $95 \% \mathrm{Cl} 1.82-9.57 ; P<0.001)$ and hospital length of stay (mean difference 0.86 days, $95 \% \mathrm{Cl} 0.13-1.59 ; P=0.02$ ) [77]. However, there was no observed effect on mortality (OR 1.92, $95 \%$ Cl 0.71-5.23; $P=0.20)$. Chaudhuri et al. included 7 observational studies ( $n=5662$ patients) in their meta-analysis and found that prophylactic endotracheal intubation was associated with significantly higher rates of pneumonia (OR 6.58, $95 \%$ $\mathrm{Cl}$ 4.91-8.81), longer hospital length of stay (mean difference, 0.96 days, $95 \% \mathrm{Cl} 0.26-1.67$ ), and increased mortality (OR $2.59,95 \% \mathrm{Cl} 1.01-6.64$ ) [76]. However, because of the observational design of the included studies, the data should be considered to be of low quality.

\section{Prokinetic medications}

\section{RECOMMENDATION}

ESGE recommends pre-endoscopy administration of intravenous erythromycin in selected patients with clinically severe or ongoing active UGIH.

Strong recommendation, high quality evidence.

In patients with acute $\mathrm{UGIH}$, the quality of the endoscopic examination can be adversely affected by poor visibility in the upper GI tract due to blood, clots and fluids. It is reported that in $3 \%$ to $19 \%$ of UGIH cases, no obvious cause of bleeding is identified $[80,81]$. This may in part be related to the presence of blood and clots impairing endoscopic visualization. Prokinetics may improve gastric mucosa visualization by inducing gastric emptying. Most studies assessing the use of pre-endoscopy prokinetics in UGIH have used erythromycin. Insufficient data were found to make recommendations for the use of metoclopramide [82-84].

Five published meta-analyses have evaluated the role of prokinetic agent infusion prior to upper $\mathrm{Gl}$ endoscopy in patients presenting with acute UGIH [82-86]. The most recently published meta-analysis ( $n=598$ patients) by Rahman et al., showed that erythromycin infusion prior to upper endoscopy significantly improved gastric mucosa visualization (OR 4.14, $95 \% \mathrm{Cl} 2.01-8.53 ; P<0.01)$, reduced the need for a secondlook endoscopy (OR 0.51, 95\%Cl 0.34-0.77; $P<0.01$ ), and reduced the length of hospital stay (mean difference $-1.75,95 \%$ $\mathrm{Cl}-2.43$ to -1.06 ; $P<0.01$ ) [86]. However other relevant outcomes, such as duration of the procedure, units of blood transfused, and need for emergency surgery showed no significant differences. Mortality was not assessed.

A single intravenous dose of erythromycin appears to be safe and generally well tolerated, with no adverse events reported in 
the meta-analyses. Most studies that reported a significant improvement in endoscopic visualization with pre-endoscopic erythromycin infusion did include patients admitted to the intensive care unit because of acute UGIH with clinical evidence of active bleeding or hematemesis. These are the patients most likely to benefit from erythromycin infusion prior to endoscopy. The dose of erythromycin most commonly used is $250 \mathrm{mg}$, infused 30-120 minutes prior to upper Gl endoscopy. A costeffectiveness study found that pre-endoscopy erythromycin infusion in UGIH was cost-effective, primarily because of a reduction in the need for second-look endoscopy [87].

It should be noted that there have been difficulties accessing erythromycin in many countries. Furthermore, there are some contraindications to its administration. These include patient sensitivity to macrolide antibiotics and presence of a prolonged QT interval. Drug interactions such as erythromycin-induced digoxin toxicity have been reported to occur when erythromycin is repeatedly administrated, although the risk appears to be very low [88]. In addition, the combination of simvastatin and erythromycin may increase the risk of rhabdomyolysis [89].

\section{Endoscopic management}

\section{Timing of upper $\mathrm{Gl}$ endoscopy}

\section{RECOMMENDATION}

ESGE recommends adopting the following definitions regarding the timing of upper Gl endoscopy in acute UGIH relative to the time of patient presentation: urgent $\leq 12$ hours, early $\leq 24$ hours, and delayed $>24$ hours. Strong recommendation, moderate quality evidence.

\section{RECOMMENDATION}

ESGE recommends that following hemodynamic resuscitation, early ( $\leq 24$ hours) upper $\mathrm{Gl}$ endoscopy should be performed.

Strong recommendation, high quality evidence.

\section{RECOMMENDATION}

ESGE does not recommend urgent ( $\leq 12$ hours) upper GI endoscopy since as compared to early endoscopy, patient outcomes are not improved.

Strong recommendation, high quality evidence.

\section{RECOMMENDATION}

ESGE does not recommend emergent ( $\leq 6$ hours) upper GI endoscopy since this may be associated with worse patient outcomes.

Strong recommendation, moderate quality evidence.

\section{RECOMMENDATION}

ESGE recommends that the use of antiplatelet agents, anticoagulants, or a predetermined international normalized ratio (INR) cutoff level, should not be used to define or guide the timing of upper Gl endoscopy in patients with acute UGIH.

Strong recommendation, low quality evidence.

In patients with acute NVUGIH, upper GI endoscopy performed within 24 hours or after 24 hours of patient presentation are the commonly accepted definitions for "early" and "delayed" endoscopy [90-95]. Urgent upper GI endoscopy in the setting of acute UGIH has been variably defined as endoscopy performed between 6-12 hours of patient presentation $[91,96,97]$. There is no consensus definition of emergent endoscopy.

Early endoscopy ( $\leq 24$ hours from the time of patient presentation) is associated with lower in-hospital mortality, shorter length of stay, and lower total hospital costs, and should be performed in patients with acute UGIH [92-94]. A beneficial role of urgent endoscopy ( $\leq 12$ hours from the time of patient presentation) however, is not routinely demonstrated as published studies show conflicting results. While one recent study concluded that urgent endoscopy was an independent predictor of lower mortality [96], other studies have shown that urgent endoscopy was a predictor of worse patient outcomes $[90,97]$, or that clinical outcomes were not significantly different between urgent and early endoscopy [91]. Moreover, in a well-executed large RCT by Lau et al., the investigators reported that, at 30-day follow-up, as compared to "early" upper endoscopy (mean time to endoscopy $24.7 \pm 9.0$ hours), "urgent" upper endoscopy (mean time to endoscopy $9.9 \pm 6.1$ hours) performed in patients at high risk for further bleeding or death, was not associated with significantly lower rates of further bleeding (7.8\% vs. $10.9 \%$; HR $1.46,95 \% \mathrm{Cl} 0.83-2.58)$ or lower mortality (6.6\% vs. $8.9 \%$; HR 1.35 , $95 \% \mathrm{Cl} 0.72-2.54$ ) [98]. Lastly, in a large prospective cohort study from Denmark, including 12601 patients admitted to hospital with peptic ulcer bleeding, emergent endoscopy (performed $<6$ hours from the time of patient presentation) was associated with higher inhospital and 30-day mortality, particularly in hemodynamically unstable patients or in patients with an American Society of Anesthesiologists (ASA) score $\geq 3$ [99]. In those patients, optimizing hemodynamic resuscitation and adequately attending to comorbidities prior to endoscopy may improve outcomes.

Although antiplatelet and anticoagulant therapies are usually interrupted or discontinued in patients with acute $\mathrm{UGIH}$, it is now realized that complete reversal of the antithrombotic effect of those drugs is not necessary for performance of diagnostic and therapeutic endoscopy. One study evaluated the risk of rebleeding in patients receiving anticoagulants and concluded that an INR > 2.5 was not a risk factor for rebleeding in patients with acute UGIH [49]. This finding, combined with the fact that the antithrombotic effect of DOACs is not measured by INR, has led to the recommendation to avoid using a predetermined INR 
cutoff value to define the timing of endoscopy in the setting of acute UGIH.

\section{On-call GI endoscopy resources}

\section{RECOMMENDATION}

ESGE recommends the availability of both an on-call GI endoscopist proficient in endoscopic hemostasis and oncall nursing staff with technical expertise in the use of endoscopic devices, to allow performance of endoscopy on a 24/7 basis.

Strong recommendation, low quality evidence.

Although a retrospective study from Japan concluded that the clinical outcomes of patients who underwent emergency endoscopic hemostasis for acute UGIH outside regular hours did not differ from those of patients treated during regular hours [100], two systematic reviews/meta-analyses found otherwise [95, 101]. Xia et al. reported that NVUGIH patients who were admitted out of hours had significantly higher mortality and received less timely endoscopy [95]. Shih and colleagues showed that the "weekend effect" was associated with increased mortality in UGIH patients, particularly in patients with NVUGIH [101].

\section{Endoscopic diagnosis}

\section{RECOMMENDATION}

ESGE recommends the Forrest (F) classification be used in all patients with peptic ulcer hemorrhage to differentiate low risk and high risk endoscopic stigmata.

Strong recommendation, high quality evidence.

\section{RECOMMENDATION}

ESGE recommends that peptic ulcers with spurting or oozing bleeding (Fla or Flb, respectively) or with a nonbleeding visible vessel (FIla) receive endoscopic hemostasis because these lesions are at high risk for persistent bleeding or recurrent bleeding.

Strong recommendation, high quality evidence.

\section{RECOMMENDATION}

ESGE suggests that peptic ulcers with an adherent clot (FIlb) be considered for endoscopic clot removal. Once the clot is removed, any identified underlying active bleeding (Fla or Flb) or nonbleeding visible vessel (FIla) should receive endoscopic hemostasis.

Weak recommendation, moderate quality evidence.

\section{RECOMMENDATION}

ESGE does not recommend endoscopic hemostasis in patients with peptic ulcers having a flat pigmented spot (FIIC) or clean base (FIII), as these stigmata have a low risk of adverse outcomes. In selected clinical settings these patients may have expedited hospital discharge. Strong recommendation, moderate quality evidence.

\section{RECOMMENDATION}

ESGE does not recommend the routine use of Doppler endoscopic probe in the evaluation of endoscopic stigmata of peptic ulcer bleeding.

Strong recommendation, low quality evidence.

\section{RECOMMENDATION}

ESGE does not recommend the routine use of capsule endoscopy technology in the evaluation of acute UGIH. Strong recommendation, low quality evidence.

The Forrest (F) classification was developed more than 40 years ago to standardize the endoscopic characterization of peptic ulcers [102]. The Forrest classification is defined as follows: Fla spurting hemorrhage, Flb oozing hemorrhage, Flla nonbleeding visible vessel, Fllb adherent clot, Fllc flat pigmented spot, and FIII clean base ulcer. This classification has been used in numerous studies to identify patients at risk of persistent ulcer bleeding, recurrent ulcer bleeding, and mortality. Most of these studies have shown that the presence of an ulcer endoscopically classified as Fla or Flb is an independent risk factor for persistent bleeding or recurrent bleeding [103]. A potential limitation of the Forrest classification is that recognition and identification of endoscopic stigmata and interobserver agreement may be less than optimal, although data are conflicting $[104,105]$.

The classification of Flb as a high risk stigma following endoscopic therapy is controversial. It is apparent that Flb stigmata require endoscopic hemostasis as there is active bleeding (i.e., oozing hemorrhage), but the response to endoscopic treatment may be different compared to that with other high risk endoscopic stigmata of hemorrhage (Fla, Flla, and in some cases Fllb), specifically in peptic ulcer rebleeding rates. An RCT including 388 patients comparing PPI or placebo following successful endoscopic treatment of Flb ulcers found no apparent benefit on rebleeding rates with the addition of PPI (5.4\% vs. $4.9 \%$; OR 1.11, 95\% Cl 0.42-2.95) [106]. In the placebo group, Flb ulcers had a lower risk of rebleeding (4.9\%) compared to Fla (22.5\%), Fllb (17.6\%), and Flla (11.3\%). Studies using a Doppler endoscopic probe have shown rebleeding rates from Flb ulcers following endoscopic therapy to be lower than the rebleeding rates of Fla, Flla and Fllb ulcers. This has led some to consider 
a reassessment of the risk stratification of endoscopic stigmata of recent hemorrhage as follows: "high risk," Fla, Flla, and Fllb; "medium risk," Flb and Fllc; and "low risk," FIII $[106,107]$. A prospective study, that included two patient cohorts with 87 high risk stigmata (Fla, Flla, Fllb) ulcers and 52 medium risk stigmata (FIb, Fllc) ulcers, demonstrated significantly higher Doppler signal-positive arteries in high risk stigmata ulcers compared to the medium risk stigmata ulcers, before endoscopic hemostasis $(87.4 \%$ vs. $42.3 \%, P<0.001)$ as well as after endoscopic hemostasis ( $27.4 \%$ vs. $13.6 \%$ ), and significantly higher 30 -day rebleeding rates $(28.6 \%$ vs. $0 \%, P=0.04)$. In addition, for spurting bleeding (Fla) versus oozing bleeding (Flb), baseline Doppler endoscopic probe arterial flow was $100 \%$ versus $46.7 \%$, residual blood flow detected after endoscopic hemostasis was $35.7 \%$ versus $0 \%$, and 30 -day rebleed rates were $28.6 \%$ versus $0 \%$ (all $P<0.05$ ) [107]. However, given the low numbers of patients included in this study, larger size studies are needed before considering a change in endoscopic stigmata risk classification.

In addition to the Forrest classification, there are additional endoscopic features of peptic ulcers that can predict adverse outcomes and/or endoscopic treatment failure and recent publications continue to support this $[108,109]$. These endoscopic features include large size of ulcer $(>2 \mathrm{~cm})$, large size of nonbleeding visible vessel, and ulcer location on the posterior duodenal wall or the proximal lesser curvature of the stomach.

The persistence of a positive Doppler probe signal following endoscopic hemostasis has been shown to predict recurrent bleeding [110]. The results of available studies have been disparate and limited by their methodology, the older endoscopic hemostasis therapies used, and the small numbers of patients included. However, two recent studies have used a throughthe-scope (TTS) Doppler probe to guide endoscopic hemostasis. In an RCT with a subgroup of 86 patients with peptic ulcer bleeding, 53 were classified as "high risk" (Fla, Flla, Fllb) and 23 as "medium risk" (Flb, Fllc). Patients were randomly assigned to standard endoscopic hemostasis or Doppler probeguided hemostasis with repeat intervention until the Doppler signal was completely obliterated. Total rebleeding rates were significantly lower in the Doppler probe-guided hemostasis group ( $11.1 \%$ vs. $26.3 \%, P=0.02$ ) but there were no significant differences in other outcomes [111]. In a study comprising 60 patients with Fla, Flb, and Flla ulcers that were "assigned by chance" to standard endoscopic hemostasis $(n=25)$ or Doppler probe-guided intervention ( $n=35)$ until the Doppler signal was obliterated, the Doppler probe-guided hemostasis group showed significantly lower rates for rebleeding (52\% vs. $20 \%$, $P=0.013$ ) and surgery ( $2 \%$ vs. $26 \%, P=0.02$ ) [112]. A costminimization analysis suggests a per-patient cost-saving with the use of the Doppler endoscopic probe in patients with peptic ulcer bleeding, but cost-savings may be dependent on and limited to specific healthcare settings [113].

Since publication of the previous ESGE NVUGIH Guideline, five additional studies have been published that evaluate the role of capsule endoscopy technology (e.g., video capsule endoscopy, magnetically assisted capsule endoscopy, telemetric sensor capsule) in acute $\mathrm{UGIH}$, namely one RCT, three prospective cohort studies, and one retrospective case series [114-118]. In the only RCT, Marya et al. reported on 87 patients with nonhematemesis $\mathrm{GI}$ hemorrhage who were randomized to early video capsule endoscopy or to "standard of care" whereby the gastroenterologist chose which procedures to perform and when to perform them based on the patient's presentation [114]. A source of Gl bleeding was located in $64.3 \%$ of the patients in the early video capsule endoscopy arm and in $31.1 \%$ of the patients in the standard of care arm $(P<0.01)$. Moreover, the likelihood of endoscopic location of bleeding over time was greater for patients receiving early video capsule endoscopy (adjusted hazard ratio 2.77, 95\%Cl 1.36-5.64). Overall, patients who received capsule endoscopy technology to evaluate their Gl bleeding were more likely to undergo therapeutic procedures (e.g., balloon enteroscopy, colonoscopy, or surgery) than patients with standard of care treatment. Thus, capsule endoscopy technology may be helpful in the setting of acute $\mathrm{UGIH}$, as it may assist in the clinical management plan. However, because data continue to be limited, including on costs and on availability of technology, the exact role for capsule endoscopy modalities in evaluating patients presenting with acute UGIH remains unknown. Additional high level studies are needed to further assess the diagnostic role of capsule endoscopy in this patient population.

\section{Endoscopic therapy for peptic ulcer hemorrhage}

\section{RECOMMENDATION}

Fla, Flb (active bleeding)

(a) ESGE recommends for patients with actively bleeding ulcers (Fla, Flb), combination therapy using epinephrine injection plus a second hemostasis modality (contact thermal or mechanical therapy) .

Strong recommendation, high quality evidence.

(b) ESGE suggests that in selected actively bleeding ulcers (Fla, Flb), specifically those $>2 \mathrm{~cm}$ in size, with a large visible vessel $>2 \mathrm{~mm}$, or located in a high risk vascular area (e.g., gastroduodenal, left gastric arteries), or in excavated/fibrotic ulcers, endoscopic hemostasis using a cap-mounted clip should be considered as first-line therapy.

Weak recommendation, low quality evidence.

\section{RECOMMENDATION}

Flla (nonbleeding visible vessel)

ESGE recommends, for patients with an ulcer with a nonbleeding visible vessel (FIla), contact or noncontact thermal therapy, mechanical therapy, or injection of a sclerosing agent, each as monotherapy or in combination with epinephrine injection.

Strong recommendation, high quality evidence. 


\section{RECOMMENDATION}

ESGE does not recommend that epinephrine injection be used as endoscopic monotherapy. If used, it should be combined with a second endoscopic hemostasis modality. Strong recommendation, high quality evidence.

\section{RECOMMENDATION}

ESGE recommends that "persistent bleeding" be defined as ongoing active bleeding refractory to standard hemostasis modalities.

Strong recommendation, high quality evidence.

\section{RECOMMENDATION}

ESGE suggests that in patients with persistent bleeding refractory to standard hemostasis modalities, the use of a topical hemostatic spray/powder or cap-mounted clip should be considered.

Weak recommendation, low quality evidence.

\section{RECOMMENDATION}

ESGE recommends that in patients with persistent bleeding refractory to all modalities of endoscopic hemostasis, transcatheter angiographic embolization (TAE) should be considered. Surgery is indicated when TAE is not locally available or after failed TAE.

Strong recommendation, moderate quality evidence.

Endoscopic hemostasis can be achieved using injection, thermal, and/or mechanical modalities, and it has been well demonstrated that any endoscopic hemostasis therapy is superior to pharmacotherapy alone in patients with Fla, Flb and Flla ulcers $[119,120]$. Meta-analyses show that thermal devices (contact and noncontact), injectable agents other than epinephrine (i.e., sclerosing agents, thrombin/fibrin glue), and clips are all effective methods for achieving durable hemostasis, with no single modality being superior [119-123]. Epinephrine injection therapy is effective at achieving primary hemostasis, but inferior to other endoscopic hemostasis monotherapies or combination therapy in preventing ulcer rebleeding $[119,120,122]$. Therefore, current evidence-based guidelines recommend that if epinephrine is used to treat peptic ulcer bleeding with high risk stigmata, it should only be used in combination with a second endoscopic hemostasis modality and not as monotherapy $[1,15]$.

- Fig. 3 a-c presents an algorithm, stratified according to the Forrest classification of endoscopic stigmata, for the endoscopic management of NVUGIH secondary to peptic ulcer.

Two recent meta-analyses support the superiority of combination endoscopic therapy (injection plus thermal therapy, and injection plus mechanical therapy) over epinephrine injection monotherapy in peptic ulcers with high risk stigmata [124, 125]. Baracat et al. performed a systematic review and metaanalysis of 28 RCTs that included 2988 adults with high risk peptic ulcer endoscopic stigmata. These authors reported that injection therapy alone, as compared to injection plus thermal therapy was inferior in terms of ulcer rebleeding (risk difference $[R D]-0.08,95 \% \mathrm{Cl}-0.14$ to -0.02$)$ and need for emergency surgery (RD $-0.06,95 \% \mathrm{Cl}-0.12$ to 0.00 ). Moreover, they reported that injection therapy alone, as compared to injection plus mechanical therapy was also inferior in terms of rebleeding ( $R D-0.10,95 \% \mathrm{Cl}-0.018$ to -0.03 ) and need for surgery (RD $-0.11,95 \% \mathrm{Cl}-0.18$ to -0.04 ) [124]. No significant difference in mortality between hemostasis modalities was observed. In a network meta-analysis, Shi et al. reported that the addition of mechanical therapy following epinephrine injection significantly reduced the probability of rebleeding and surgery $(\mathrm{OR} 0.19,95 \% \mathrm{Cl} 0.07-0.52$ and $\mathrm{OR}$ $0.10,95 \% \mathrm{Cl} 0.01-0.50$, respectively), while the addition of thermal therapy only reduced ulcer rebleeding rates (OR $0.30,95 \% \mathrm{Cl} 0.10-0.91$ ) [125].

With respect to noncontact thermal therapy (e.g., argon plasma coagulation [APC]), limited data from three previous small RCTs suggest that in peptic ulcer hemorrhage, APC may provide similar efficacy to injection of a sclerosing agent (polidocanol) or contact thermal therapy (heater probe) [119]. More recently, a single RCT (noninferiority design) compared combination endoscopic therapies using epinephrine injection plus APC versus epinephrine injection plus soft coagulation using hemostatic forceps [126]. That study included 151 patients with high risk stigmata gastroduodenal ulcers (Fla, Flb, Flla). The authors reported similar outcomes between APC and hemostatic forceps for rates of primary hemostasis $(96.0 \%$ vs. $96.1 \%, P=1.00)$, 7-day ulcer rebleeding $(4.0 \%$ vs. $6.6 \%$, $P=0.72)$ and 30 -day ulcer rebleeding rates $(6.7 \%$ vs. $9.2 \%$, $P=0.56)$.

Clinicians must distinguish between two clinical scenarios in NVUGIH: persistent bleeding and recurrent bleeding. Persistent bleeding is defined as ongoing active bleeding (spurting, arterial pulsatile bleeding, or oozing) that is present at the end of index endoscopy and refractory to standard hemostasis modal-

- Fig. 3 Algorithm for the endoscopic management of nonvariceal upper gastrointestinal hemorrhage (NVUGIH) secondary to peptic ulcer, stratified by Forrest classification endoscopic stigmata: a Fla, Flb, Flla; b Fllb; c Fllc, FIII. 'Use of a large single-channel or double-channel therapeutic upper gastrointestinal endoscope is recommended. ${ }^{2}$ Large-size $10-\mathrm{Fr}$ probe recommended for contact thermal therapy. ${ }^{3} \mathrm{Absolute}$ alcohol, polidocanol, or ethanolamine injected in limited volumes. ${ }^{4}$ The benefit of endoscopic hemostasis may be greater in patients at higher risk for recurrent bleeding, e. g., with older age, comorbidities, in-hospital UGIH. GI, gastrointestinal; PPI, proton pump inhibitor, TAE, transcatheter angiographic embolization. 
Performance of upper $\mathrm{Gl}$ endoscopy ${ }^{1}$

\section{$\sqrt{2}$}

High risk endoscopic stigmata

Fla (active spurting, pulsatile arterial bleeding) Flb (active oozing)

Flla (nonbleeding visible vessel)

\section{Perform endoscopic hemostasis}

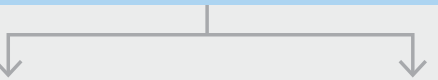

\section{Fla and Flb stigmata}

Combination therapy using dilute epinephrine injection + a second hemostasis modality (thermal ${ }^{2}$, mechanical or sclerosant injection ${ }^{3}$ )

$\checkmark$

$$
\downarrow
$$

\section{Flla stigmata}

Thermal ${ }^{2}$, mechanical, or sclerosant injection ${ }^{3}$ as monotherapy or in combination with dilute epinephrine injection

- High dose PPI (intravenous bolus + continuous infusion or minimum twice-daily intravenous bolus dosing for 72 hours or oral dosing)

- May start clear liquids soon after endoscopy

- Test for Helicobacter pylori at index endoscopy, treat if positive; document $H$. pylori eradication

- If negative $H$. pylori test at index endoscopy, repeat testing within 4 weeks following the acute bleeding episode to confirm initial test was true negative

If clinical evidence of rebleeding, repeat endoscopy with endoscopic hemostasis if indicated;

If endoscopic hemostasis still unsuccessful, refer for TAE if locally available, otherwise refer for surgery
Performance of upper GI endoscopy ${ }^{1}$

$\sqrt{ }$

Fllb (adherent clot)

Consider performing clot removal followed by endoscopic hemostasis of underlying high risk stigmata ${ }^{4}$ OR

Medical management with high dose PPI (intravenous bolus + continuous infusion for 72 hours or minimum twice-daily intravenous bolus dosing for 72 hours or oral dosing)

If clot removal/endoscopic hemostasis performed:

- Dilute epinephrine injection circumferential to base of clot followed by clot removal using cold polyp snare guillotine technique

- If underlying high risk stigmata identified after clot removal, apply endoscopic hemostasis as described for Fla, Flb, Flla stigmata

- High dose PPI (intravenous bolus + continuous infusion or minimum twice-daily intravenous bolus dosing for 72 hours or oral dosing)

- May start clear liquids soon after endoscopy

- Test for $H$. pylori, treat if positive; document H. pylori eradication

- If negative $H$. pylori test at index endoscopy, repeat testing within 4 weeks following the acute bleeding episode to confirm initial test was true negative

If clinical evidence of rebleeding, repeat endoscopy with endoscopic hemostasis if indicated;

If endoscopic hemostasis still unsuccessful, refer for TAE if locally available, otherwise refer for surgery

Performance of upper GI endoscopy'

\section{$\checkmark$}

\section{Low risk stigmata}

Fllc (flat pigmented spot)

FIII (clean base)

No endoscopic hemostasis required

In select clinical settings, these patients may have expedited hospital discharge

- Start oral PPI

- Start regular diet

- Test for H. pylori, treat if positive; document H. pylori eradication

- If negative H. pylori test at index endoscopy, repeat testing within 4 weeks following the acute bleeding episode to confirm initial test was true negative

C 
ities. This is also referred to as "failed primary endoscopic hemostasis" [1]. Few RCTs have compared alternative treatment modalities in the management of patients with persistent ulcer bleeding. Meta-analyses and retrospective case series comparing transcatheter arterial embolization (TAE) and surgery suggest that patient outcomes following either approach are similar [127-129]. TAE, however, is associated with a higher failure rate in the control of bleeding [127-129]. A populationbased cohort study compared outcomes in 282 patients (97 TAE and 185 surgery) and found a 34\% lower mortality among those in the TAE group (adjusted HR 0.66, 95\% Cl 0.46-0.96). However, similarly to other cohort studies, rebleeding was higher after TAE (HR 2.48, 95\%Cl 1.33-4.62), whereas following surgery adverse events were significantly higher $(32.2 \%$ vs. $8.3 \%, P<0.001$ ) [130].

Since publication of the original ESGE NVUGIH guideline in 2015, several additional studies have reported on the clinical efficacy of topical hemostatic agents (e.g., TC-325, Endoclot, and Inha University-Endoscopic Wound Dressing [UI-EWD]) in patients with Gl bleeding secondary to peptic ulcer bleeding. These include case series, a multicenter patient registry, a pilot RCT, and a cost-effectiveness analysis [131-134]. A multicenter (12 sites) patient registry evaluated the effectiveness of TC-325 in upper and lower GI bleeding (167/314 [53\%] due to peptic ulcer) [132]. In the subgroup of peptic ulcer hemorrhage (most common stigmata, Flb), the authors reported an overall hemostasis rate of $86 \%$, an overall rebleeding rate of $12.7 \%$, and 7-day and 30-day all-cause mortality of $16.2 \%$ and $24.6 \%$, respectively. These data however should be interpreted with caution because of the inherent limitations of a patient registry that included lack of randomization or sequential patient selection, multiple bleeding indications (with Gl bleeding secondary to malignancy being over-represented in the cohort), along with patient selection bias and self-reported or unverified outcomes. In addition, a pilot RCT evaluated the clinical efficacy of TC-325 with/without epinephrine injection versus through-thescope (TTS) clipping with/without epinephrine injection, in 39 patients with active NVUGIH (the majority of cases due to peptic ulcer, and 35/39 [89.7\%] with Flb oozing bleeding) [133]. The authors reported that primary hemostasis was achieved in all TC-325 cases and in $90 \%$ of the mechanical therapy group ( $P$ $=0.49$ ). There was no difference in rebleeding, need for surgery, or mortality rates between the groups. This was a small pilot study with a limited number of patients enrolled, and thus not adequately powered to show a statistically significant difference between groups. Moreover, five patients in the TC325 group required additional endoscopic intervention at the time of second-look endoscopy, while none in the clipping group required such therapy $(P=0.04)$. These results should not be extrapolated to Fla bleeding lesions. Lastly, a decision analysis model compared the cost-effectiveness of traditional endoscopic hemostasis therapies alone, TC-325 alone, or these therapies in combination, when treating acute NVUGIH [134]. The authors reported that traditional endoscopic hemostasis complemented by TC-325 was more efficacious ( $97 \%$ avoiding rebleeding) and less expensive than comparator treatments (mean cost per patient \$9150). The second most cost-effective approach was TC-325 plus traditional endoscopic hemostasis (5.8\% less effective and $\$ 635$ more costly per patient). The limitations of topical sprays/powders are that they only bind to sites with active bleeding and usually wash away within 12-24 hours; thus they are a temporary measure.

The role of cap-mounted clips (e.g, the Over the Scope Clip [OTSC], Ovesco, Tübingen, Germany; and the Padlock system, Steris Endoscopy, Mentor, Ohio, USA) in treating NVUGIH, used as first-line and second-line (e.g., rescue/salvage) therapy, continues to evolve. In a retrospective case series evaluating over-the-scope (OTS) clip technology as first-line treatment in NVUGIH (the FLETRock study), Wedi et al. reported on 118 patients with NVUGIH, including 60 patients $(50.8 \%)$ defined as high risk based upon a Rockall risk score $\geq 8$ [135]. Primary clinical success (hemostasis by OTS clipping alone) was achieved in 107 patients (90.8\%) and secondary clinical success (hemostasis by OTS clipping in combination with adjunctive measures) in 7 patients (1.7\%). In $7.5 \%$ of clip applications, the bleeding could not be stopped and treatment was defined as clinical failure. Patients with Forrest la active bleeding were at higher risk of rebleeding (11/31 patients, 35.5\%). Manta et al., in a multicenter retrospective study, also reported on the outcomes of 286 patients $(74.8 \%$ with NVUGIH) who were treated with OTS clipping as first-line endoscopic hemostasis therapy [136]. Of the 214 patients with NVUGIH, technical success was achieved in 208 (97.2\%), including 202/208 (97.1\%) achieving hemostasis with OTS clipping as monotherapy. Early rebleeding, within 24 hours, occurred in 9 patients (4.5\%), and no delayed bleeding (within 30 days) was reported. Technical failure of OTS clipping occurred in 6 patients, in ulcers located in the gastric fundus or posterior wall of the duodenal bulb. Brandler et al. reported an additional retrospective case series of 67 patients (60 patients with NVUGIH, including 49 due to peptic ulcer, 11 with Forrest la active bleeding) with bleeding lesions defined by the authors as being at "high risk of adverse outcome" (visible vessel > 2 mm; ulcer location in high risk vascular region, including gastroduodenal, left gastric arteries; penetrating, excavated or fibrotic ulcer with high risk stigmata) [137]. OTS clipping was performed as first-line therapy in 49 patients. The authors reported $100 \%$ technical success, OTS clipping success (no bleeding related to OTS clipping requiring re-intervention) in 52 patients (81.3\%), and true success (no bleeding within 30 days) in 46 patients (71.8\%). They reported no adverse events.

In a systematic review and meta-analysis, Chandrasekar et al. examined the effectiveness of cap-mounted clip technology in achieving "definitive hemostasis" in Gl bleeding, defined as successful primary hemostasis without rebleeding during the follow-up period (median 56 days) [138]. This meta-analysis included 21 studies ( 1 RCT, 20 observational) with 851 patients (687 with UGIH). In those patients with UGIH, OTS clipping was used as first-line endoscopic therapy in $75.8 \%$ and definitive hemostasis was achieved in $86.6 \%$ (95\% Cl 81.9-91.3). The rebleeding rate in patients with UGIH was $11.0 \%$ (95\% Cl $6.8 \%-$ $15.2 \%)$. The OTSC failure rate for UGIH was $6.2 \%(95 \% \mathrm{Cl} 3.1 \%-$ $9.2 \%)$ and $16.9 \%(95 \% \mathrm{Cl} 9.3 \%-24.5 \%)$ for first- and second-line therapy, respectively. It must be noted that this meta-analysis is 
limited, as all included studies but one were observational in design. Other observational studies have also reported on the efficacy and safety of OTSC used as either first-line or second-line hemostasis treatment, with similar findings [139-144].

Very recently, the first blinded RCT evaluating the efficacy and safety of a cap-mounted clip (OTS clip, $n=25$ ) versus standard endoscopic hemostasis therapy (TTS clip or contact thermal therapy using multipolar electrocoagulation, $n=28$ ) for firstline treatment of acute peptic ulcer or Dieulafoy bleeding was published by Jensen et al. [145]. The investigators reported that compared to standard endoscopic hemostasis, there was both significantly less recurrent bleeding within 30 days (1/25 [4.0\%] vs. 8/28 [28.6\%], $P=0.017)$ and fewer adverse events $(0 / 25$ [0\%] vs. $4 / 28$ [14.3\%], $P=0.049)$ in the OTS clip group. There were no observed differences in need for surgery or mortality. However, a number of methodological limitations to this study must be noted, including the relatively limited number of patients, the inclusion of Dieulafoy lesions in addition to peptic ulcers, and the use of unconventional definitions of "major" endoscopic stigmata of recent hemorrhage that are not widely adopted.

In a multicenter RCT from Europe and Asia (the STING study), Schmidt et al. reported on 66 patients with recurrent peptic ulcer hemorrhage following initially successful endoscopic hemostasis, who were randomly assigned to undergo hemostasis with either OTS clipping $(n=33)$ or standard endoscopic therapy (using TTS clips, $n=31$, or contact thermal therapy plus injection with dilute epinephrine, $n=2$ ) [146]. By perprotocol analysis, persistent ulcer bleeding was observed in 14 patients $(42.4 \%)$ in the standard therapy group and 2 patients $(6.0 \%)$ in the OTS clip group $(P=0.001)$. Recurrent ulcer bleeding within 7 days occurred in 5 patients $(16.1 \%)$ in the standard therapy group versus 3 patients $(9.1 \%)$ in the OTS clip group ( $P$ $=0.47)$. Further bleeding occurred in 19 patients $(57.6 \%)$ in the standard therapy group and in 5 patients (15.2\%) in the OTS clip group (absolute difference $42.4 \%$, $95 \% \mathrm{Cl} 21.6 \%-63.2 \%$; $P$ $=0.001)$. During 30 days of follow-up, 1 patient $(3.0 \%)$ in the standard therapy group and 1 patient $(3.0 \%)$ in the OTS clip group required surgery $(P=0.99), 2$ patients $(6.3 \%)$ died in the standard therapy group and 4 patients $(12.1 \%)$ died in the OTSC group $(P=0.67)$.

To date, almost all evidence on the efficacy of OTS clipping is derived from case series or case series compared with historical controls. Randomized trials directly comparing topical agents and OTS clips/clamps with traditional hemostasis therapies are required to better define their true efficacies and safety in both first-line and second-line endoscopic management of acute

\section{RECOMMENDATION}

ESGE suggests considering the use of hemostatic forceps as an alternative endoscopic hemostasis option in peptic ulcer hemorrhage

Weak recommendation, moderate quality evidence.

NVUGIH, especially peptic ulcer bleeding.
In 2015, the previously published ESGE guideline on NVUGIH reported on two small studies that compared the efficacy of mechanical therapy versus hemostatic forceps in peptic ulcer hemorrhage $[147,148]$. The first was an RCT conducted in 96 patients with high risk bleeding gastric ulcers; it showed that use of monopolar, soft coagulation hemostatic forceps was as effective as mechanical therapy [147]. The second study was a prospective cohort study including 50 patients in whom use of bipolar hemostatic forceps was more effective than endoscopic clipping, for both initial hemostasis ( $100 \%$ vs. $78.2 \%, P<0.05)$ and preventing recurrent bleeding (3.7\% vs. $22.2 \%, P$ not significant) [148]. More recently, three additional RCTs have evaluated the efficacy of hemostatic forceps in peptic ulcer hemorrhage. Nunoe et al. reported on 111 patients with peptic ulcer hemorrhage; compared to contact thermal therapy (i. e., heater probe), hemostatic forceps achieved a significantly higher rate of primary hemostasis ( $96 \%$ vs. $67 \%, P<0.001)$ and lower ulcer rebleeding rates (0 vs. 12\%) [149]. Kim et al, included 151 patients and failed to show any significant difference in rates of primary hemostasis, rebleeding, adverse events, or mortality between argon plasma coagulation (APC) and hemostatic forceps [150]. Finally, Toka et al. compared epinephrine injection plus hemostatic forceps to epinephrine injection plus mechanical therapy using TTS clips, in 112 patients, and demonstrated that as compared to mechanical therapy, hemostatic forceps achieved significantly higher rates of primary hemostasis (98.2\% vs. $80.4 \%, P=0.004)$ and significantly lower ulcer rebleeding (3.6\% vs. $17.7 \%, P=0.04$ ) [151].

Box 1 presents a description of the endoscopic hemostatic modalities.

\section{Post-endoscopy management Proton pump inhibitor therapy}

\section{RECOMMENDATION}

ESGE recommends high dose proton pump inhibitor (PPI) therapy for patients who receive endoscopic hemostasis, and for patients with Fllb ulcer stigmata (adherent clot) not treated endoscopically.

(a) PPI therapy should be administered as an intravenous bolus followed by continuous infusion (e.g., $80 \mathrm{mg}$ then $8 \mathrm{mg} /$ hour) for 72 hours post endoscopy.

(b) High dose PPI therapies given as intravenous bolus dosing (twice-daily) or in oral formulation (twice-daily) can be considered as alternative regimens.

Strong recommendation, high quality evidence.

Previously published evidence-based guidelines on NVUGIH recommended that PPI therapy, given as an $80 \mathrm{mg}$ intravenous bolus followed by $8 \mathrm{mg} /$ hour continuous infusion, be used to decrease ulcer rebleeding and mortality in patients with high risk endoscopic stigmata who had undergone successful endoscopic hemostasis $[1,15]$. Meta-analyses of RCTs comparing low dose $(80 \mathrm{mg} /$ day or lower) to high dose PPI (> $80 \mathrm{mg} /$ day), suggest that patient-centered outcomes were similar following 


\section{BOX 1 ENDOSCOPIC HEMOSTASIS TOOLBOX}

\section{Injection therapy}

The primary mechanism of action of injection therapy is local tamponade resulting from a volume effect. Diluted epinephrine (1:10 000 or 1:20 000 with normal saline injected in $0.5-2-\mathrm{ml}$ aliquots in and around the ulcer base) may also have a secondary effect that produces local vasoconstriction. Sclerosing agents such as ethanol, ethanolamine, and polidocanol produce hemostasis by causing direct tissue injury and thrombosis. Another class of injectable agents are tissue adhesives including thrombin, fibrin, and cyanoacrylate glues, which are used to create a primary seal at the site of bleeding.

Endoscopic injection is performed using needles which consist of an outer sheath and an inner hollow-core needle (19-25 gauge). The endoscopist or nursing assistant retracts the needle into the plastic sheath for safe passage through the working channel of the endoscope. When the catheter is passed out of the working channel and placed near the site of bleeding, the needle is extended out of the sheath and the solution injected into the mucosa using a syringe attached to the catheter handle.

\section{Thermal therapy}

Thermal devices are divided into contact and noncontact modalities. Contact thermal devices include heater probes that generate heat directly, multipolar/bipolar electrocautery probes that generate heat indirectly by passage of an electrical current through the tissue, and monopolar/bipolar hemostatic forceps. Noncontact thermal devices include argon plasma coagulation. Heat generated from these devices leads to edema, coagulation of tissue proteins, vasoconstriction, and indirect activation of the coagulation cascade, resulting in a hemostatic bond. Contact thermal probes also use local tamponade (mechanical pressure of the probe tip directly onto the bleeding site) combined with heat or electrical current to coagulate blood vessels, a process known as "coaptive coagulation."

Heater probes (available in 7-Fr and 10-Fr sizes) consist of a Teflon-coated hollow aluminum cylinder with an inner heating coil combined with a thermocoupling device at the tip of the probe to maintain a constant energy output (measured in joules, commonly delivering 15-30 J). Multipolar/bipolar electrocautery contact probes deliver thermal energy by completion of an electrical local circuit (no grounding pad required) between two electrodes on the tip of the probe as current flows through nondesiccated tissue. As the targeted tissue desiccates, there is a decrease in electrical conductivity, limiting the maximum temperature and depth and area of tissue injury. An endoscopistcontrolled foot pedal activates the heater probe, controls the delivery of the energy (measured in watts) and provides waterjet irrigation. The standard setting for use in achieving hemostasis in peptic ulcer bleeding is 15-20 watts, which is delivered in 8-10-second applications (commonly referred to as tamponade stations).

Monopolar/bipolar hemostatic forceps are contact thermal devices widely used in the treatment of blood vessels or active bleeding during endoscopic submucosal dissection (ESD) and third-space endoscopy (e.g., peroral endoscopic myotomy [POEM]). However, studies evaluating the utility and safety of hemostatic forceps in the treatment of peptic ulcer bleeding are limited. Technically, hemostatic forceps are applied differently during treatment of bleeding in ESD/ POEM and peptic ulcers. In ESD/POEM, the vessel is grasped and gently retracted by the forceps, then soft coagulation is applied. In the treatment of peptic ulcer bleeding, soft coagulation is applied directly by contacting the bleeding point with the closed tip of the hemostatic forceps. Potential disadvantages of hemostatic forceps should be considered, including a reduced coagulation effect in the presence of blood, clots, or water between the tip of the forceps and the bleeding point. Moreover, because of the monopolar nature of some hemostatic forceps, the mode of the cardiac device needs to be adjusted in patients with pacemakers and implantable cardioverter-defibrillators.

Argon plasma coagulation (APC), a noncontact thermal modality, uses high frequency, monopolar alternating current that is conducted to the target tissue without mechanical contact, resulting in coagulation of superficial tissue. The electrons flow through a stream of electrically activated ionized argon gas, from the probe electrode to the target, causing tissue desiccation at the surface. As the tissue surface loses its electrical conductivity, the plasma stream shifts to adjacent nondesiccated (conductive) tissue, which again limits the depth of tissue injury. If the APC catheter is not near the target tissue, there is no ignition of the gas and depression of the foot pedal results only in flow of inert argon gas. Coagulation depth is dependent on the generator power setting, duration of application, and distance from the probe tip to the target tissue (optimal distance 2-8 $\mathrm{mm})$.

\section{Mechanical therapy}

Endoscopic mechanical therapies include clips (throughthe-scope [TTS] and cap-mounted) and band ligation devices. TTS endoscopic clips are deployed directly onto a bleeding site and typically slough off within days to weeks after placement. Clips are available in a variety of jaw lengths and opening widths. The delivery catheter consists of a metal cable within a sheath enclosed within a Teflon catheter. After insertion of the catheter through the working channel of the endoscope, the clip is extended out of the sheath. The clip is then positioned over the target area and opened with the plunger handle. A rotation mechanism on the handle is available on some commercially available clips and this allows the endoscopist to change the orientation of the clip at the site of bleeding. The jaws of the clip 
are applied with pressure and closed onto the target tissue by using the device handle. Some clips may be opened, closed, and repositioned, whereas others are permanently deployed and released upon clip closure. Similarly, some clips are automatically released on deployment, while others require repositioning of the plunger handle to release the deployed clip from the catheter. Hemostasis is achieved by mechanical compression of the bleeding site.

Currently two types of cap-mounted clip devices are commercially available for use in GI bleeding: the Ovesco Over The Scope Clip (OTSC) system (Ovesco Endoscopy, Tübingen, Germany) and the Padlock system (Steris Endoscopy, Mentor, Ohio, USA). These devices are similar in that they both utilize an applicator cap preloaded with a nitinol clip (either bearclaw-shaped with teeth or hexagonal in shape with circumferentially placed inner prongs) that fits onto the tip of the endoscope. However, there are some differences between these systems. In the Ovesco OTSC system, the applicator cap, with the preloaded nitinol clip, is affixed to the tip of the endoscope and incorporates a clip-release thread, which is pulled retrogradely through the working channel of the endoscope and fixed onto a handwheel mounted on the working channel access port of the endoscope. The clip is released by the endoscopist's turning the handwheel, in a manner similar to deploying a variceal ligation band. In contrast, the Padlock system deploys its hexagonally shaped clip using its "Lock-it" releasing mechanism. This is installed on the handle of the endoscope and connects to the clip by a linking cable delivery system on the outside of the endoscope. Thus, unlike the OTSC system, the Padlock does not take up the endoscope's working channel. The clips of both systems may remain attached to tissue for weeks. Deployment of a cap-mounted clip requires accurate positioning and adequate retraction of tissue into the cap of the device (either by suction or use of a retractor/anchoring device) before the clip can be properly deployed. Clipping of lesions located in difficult anatomic positions, such as the proximal lesser curvature of the stomach and the anatomic transition from the first to second part of the duodenum, can be technically challenging. Finally, endoscopic band ligation devices, commonly used in esophageal variceal bleeding, have also been reported for treatment of NVUGIH (e. g., Dieulafoy lesions). These involve the placement of elastic bands over tissue to produce mechanical compression and tamponade.

\section{Topical therapy}

Topical agents are increasingly being used for nonvariceal upper gastrointestinal hemorrhage (NVUGIH). Advantages of noncontact, spray catheter delivery of hemostatic agents include ease of use, lack of need for precise lesion targeting, access to lesions in difficult locations, and the ability to treat a larger surface area. One example of a topical agent is TC-325, also known as Hemospray (Cook Medical, Winston-Salem, North Carolina, USA), which is a proprietary, inorganic, absorbent powder that rapidly concentrates clotting factors at the bleeding site, forming a coagulum. Hemospray is applied using a hand-held device consisting of a pressurized $\mathrm{CO} 2$ canister, a TTS delivery catheter, and a reservoir for the powder cartridge. The powder is delivered by the endoscopist by pushing a button in 1-2second bursts until hemostasis is achieved. The maximum amount of TC-325 that can be safely administered during a single treatment session has not yet been established. The coagulum typically sloughs within 3 days and is naturally eliminated.

Other topical hemostatic sprays/powders include EndoClot, Ankaferd Blood Stopper, and Inha University-Endoscopic Wound Dressing (UI-EWD). EndoClot (EndoClot Plus, Santa Clara, California, USA) consists of absorbable modified polymers and is intended to be used as an adjuvant hemostatic agent to control bleeding in the Gl tract. It is a biocompatible, nonpyogenic, starch-derived compound that rapidly absorbs water from serum and concentrates platelets, red blood cells, and coagulation proteins at the bleeding site to accelerate the clotting cascade. Hemostatic sprays/powders derived from plant products/extracts have also been evaluated, such as Ankaferd Blood Stopper (Ankaferd Health Products, Istanbul, Turkey). This topical agent promotes formation of a protein mesh that acts as an anchor for erythrocyte aggregation without significantly altering coagulation factors or platelets. It is delivered onto the bleeding site via an endoscopic spray catheter until an adherent coagulum is formed. The particles are subsequently cleared from the bleeding site within hours to days. Finally, UI-EWD (NextBiomedical, Incheon, South Korea) is a biocompatible natural polymer in powder form using aldehyded dextran and succinic acid-modified L-lysine that is converted to an adhesive gel when in contact with water. The hemostatic powder is delivered via a spray catheter placed through the endoscope's working channel. It should be noted that the overall efficacy of topical agents in brisk arterial bleeding (Fla) may be limited because of the rapid "wash-away" effect of the hemostatic agent by ongoing blood flow. 
intermittent PPI administration (given either as intravenous bolus dosing or orally) $[152,153]$. In their meta-analysis of 13 RCTs of high risk bleeding ulcers treated with endoscopic hemostasis, Sachar et al. compared intermittent PPI dosing (oral or intravenous) with the post-hemostasis PPI regimen of $80 \mathrm{mg}$ intravenous bolus followed by $8 \mathrm{mg} /$ hour continuous infusion [154]. The authors reported that the RR for recurrent ulcer bleeding within 7 days for intermittent infusion of PPI versus bolus plus continuous infusion of PPI was 0.72 (upper boundary of one-sided $95 \% \mathrm{Cl}, 0.97$ ), with an absolute risk difference of -2.64. RRs for other outcomes, including radiologic/surgical intervention and mortality, showed no differences between infusion regimens. These meta-analytic data indicate that intermittent PPI therapy may be comparable to intravenous bolus plus continuous PPI infusion following endoscopic hemostasis.

Given the pharmacodynamic profile of PPIs, consideration should be given to use of a higher dose of PPI ( $80 \mathrm{mg}$ or more) given either intravenously or orally at least twice-daily [155]. These data appear to be supported by the results from an RCT (double-dummy, placebo-controlled design) that randomly assigned patients with peptic ulcer hemorrhage to high dose continuous infusion of esomeprazole versus $40 \mathrm{mg}$ of oral esomeprazole twice-daily for 72 hours (118 vs. 126 patients, respectively) following endoscopic hemostasis [156]. In that study, recurrent ulcer bleeding at 30 days was reported in $7.7 \%$ and $6.4 \%$ of patients, respectively (difference -1.3 percentage points, $95 \% \mathrm{Cl}-7.7$ to 5.1 percentage points) [156]. However, it must be pointed out this study was conducted in an all-Asian population, was not a noninferiority study design, was stopped prematurely because of difficulty in patient recruitment, and lacks sufficient sample size to detect any small difference between low dose and high dose PPI regimens.

\section{RECOMMENDATION}

ESGE does not recommend routine second-look endoscopy as part of the management of NVUGIH.

Strong recommendation, high quality evidence.

Routine second-look endoscopy is defined as a scheduled repeat endoscopic assessment of a previously diagnosed bleeding lesion usually performed within 24 hours following the index endoscopy [1]. This strategy employs repeat endoscopy regardless of the type of bleeding lesion, perceived rebleeding risk, or clinical signs of rebleeding. However, second-look endoscopy should be reserved for selected patients considered to be at high risk of recurrent bleeding. Previous studies have failed to demonstrate either a clinical or economic benefit of routine second-look endoscopy $[157,158]$. More recently, two RCTs from Asia both reported no benefit of routine secondlook endoscopy in peptic ulcer hemorrhage $[159,160]$. Chiu et al. showed similar rates of rebleeding within 30 days, in 10/153 $(6.5 \%)$ in a PPI infusion group and in 12/152 (7.9\%) in a secondlook endoscopy group $(P=0.646)$. Moreover, ICU stay, transfusion requirements, need for surgery, and mortality were also not different between the groups. However, patients in the second-look endoscopy group were discharged from hospital 1 day earlier $(P<0.001)$ [159]. Park et al. found a higher rate of rebleeding within 30 days in those patients who underwent routine second-look endoscopy (16/158 (10.2\%) vs. 9/161 (4.5\%), $P=0.13$ ) [160]. Thus, second-look endoscopy should be reserved for selected patients considered to be at high risk of recurrent bleeding. This includes patients in whom at index endoscopy there was an actively bleeding lesion, poor endoscopic visualization or an incomplete examination, or failure to identify a definitive source of hemorrhage, or when endoscopic hemostasis was considered by the endoscopist to be suboptimal.

\section{Management of recurrent bleeding}

\section{RECOMMENDATION}

ESGE recommends that recurrent bleeding be defined as bleeding following initial successful endoscopic hemostasis.

Strong recommendation, high quality evidence.

\section{RECOMMENDATION}

ESGE recommends that patients with clinical evidence of recurrent bleeding should receive repeat upper endoscopy, including hemostasis if indicated.

Strong recommendation, high quality evidence.

\section{RECOMMENDATION}

ESGE recommends that in the case of failure of this second attempt at endoscopic hemostasis, transcatheter angiographic embolization (TAE) should be considered. Surgery is indicated when TAE is not locally available or after failed TAE.

Strong recommendation, high quality evidence.

\section{RECOMMENDATION}

ESGE recommends that for patients with clinical evidence of recurrent peptic ulcer hemorrhage, use of a capmounted clip should be considered. In the case of failure of this second attempt at endoscopic hemostasis, transcatheter angiographic embolization (TAE) should be considered. Surgery is indicated when TAE is not locally available or after failed TAE.

Strong recommendation, moderate quality evidence.

As previously stated, recurrent bleeding is defined as bleeding following initial successful endoscopic hemostasis [161]. Clinical evidence for recurrent bleeding is commonly defined as follows: recurrent hematemesis or bloody nasogastric aspirate after index endoscopy; recurrent tachycardia or hypo- 
tension after achieving hemodynamic stability; melena and/or hematochezia following normalization of stool color; or a reduction in hemoglobin $\geq 2 \mathrm{~g} / \mathrm{dL}$ after a stable hemoglobin value has been attained $[1,15,33]$.

In the management of patients with recurrent peptic ulcer bleeding after successful initial endoscopic control, an RCT comparing repeat endoscopic therapy with surgery showed that $35 / 48(73 \%)$ of patients randomized to endoscopic retreatment had long-term control of their peptic ulcer bleeding, avoided surgery, and had a lower rate of adverse events as compared to the surgery-treated patients. The remaining 13 patients underwent salvage surgery because of failed repeat endoscopic hemostasis $(n=11)$ or perforation due to contact thermal therapy $(n=2)$. It is generally recommended that patients with clinical evidence of recurrent bleeding undergo repeat endoscopy and further endoscopic treatment if indicated [162].

ESGE suggests the use of either a cap-mounted clip or a topical hemostasis spray/powder when there is recurrent bleeding and standard endoscopic treatments fail to control the bleeding. As previously detailed, limited RCT data suggest cap-mounted clipping may become the first-line hemostasis therapy in recurrent peptic ulcer hemorrhage [146].

In registries and case series, the success rate of primary hemostasis with the use of a topical hemostasis powder approaches 95\%. In the GRAPHE (Groupe de Recherche Avancé des Praticiens Hospitaliers en Endoscopie) registry, which included 202 patients with various upper Gl bleeding etiologies (peptic ulcer in 75 patients [37.1\%], tumor in 61 [30.2\%], postendoscopic therapy in 35 [17.3\%], or other in 31 [15.3\%]), the primary hemostasis success rate using a topical powder (TC325) was $96.5 \%$ [163]. The topical powder was used as a salvage therapy in 108 patients (53.5\%). The rate of further bleeding was high, $26.7 \%$ by day 8 and $33.5 \%$ by day 30 . In a Spanish multicenter retrospective study of 261 patients, of whom 219 (83.9\%) presented with acute UGIH (most common causes were peptic ulcer [28\%], malignancy [18.4\%], and therapeutic endoscopy-related GIB [17.6\%]), TC-325 was used as rescue therapy in 191 patients (73.2\%) with a primary hemostasis success rate of $93.5 \%(95 \% \mathrm{Cl} 90 \%-96 \%)$. Failure at post-endoscopy days 3, 7, and 30 was $21.1 \%, 24.6 \%$, and $27.4 \%$, respectively [164]. It must be noted that following successful application of a topical hemostatic powder such as TC-325, a follow-up treatment plan is required (e.g. second-look endoscopy or referral for TAE).

There is some evidence from an RCT that in patients predicted to be at high risk of further peptic ulcer bleeding following endoscopic hemostasis, prophylactic TAE may reduce recurrent bleeding [165]. In a subgroup analysis, prophylactic TAE in patients with ulcers $15 \mathrm{~mm}$ or more in size significantly reduced the rebleeding risk from $12 / 52(23.1 \%)$ to $2 / 44$ (4.5\%) $(P=$ $0.027)$. The number needed to treat with prophylactic TAE to prevent one ulcer rebleed was 5 .

\section{Helicobacter pylori}

\section{RECOMMENDATION}

ESGE recommends, in patients with NVUGIH secondary to peptic ulcer, investigation for the presence of Helicobacter pylori in the acute setting (at index endoscopy) with initiation of appropriate antibiotic therapy when $\mathrm{H}$. pylori is detected.

Strong recommendation, high quality evidence.

\section{RECOMMENDATION}

ESGE recommends re-testing for $\mathrm{H}$. pylori in those patients with a negative test at index endoscopy. Strong recommendation, high quality evidence.

\section{RECOMMENDATION}

ESGE recommends documentation of successful $H$. pylori eradication.

Strong recommendation, high quality evidence.

The value and cost-effectiveness of $H$. pylori eradication in patients with peptic ulcer bleeding is well established [166168]. An updated Cochrane database systematic review, including 55 RCTs, that evaluated the benefits of eradication therapy in $\mathrm{H}$. pylori-associated peptic ulcer was published by Ford and colleagues [169]. In duodenal ulcers, eradication therapy was found superior to both ulcer-healing drugs and no treatment. Furthermore, eradication therapy prevented recurrence of both gastric and duodenal ulcers more effectively compared to no treatment. However, results of this systematic review did not demonstrate superiority of eradication therapy in gastric ulcer healing and prevention of duodenal ulcer recurrence compared to ulcer-healing medications.

The consequences of delayed testing for $\mathrm{H}$. pylori and initiation of eradication therapy in patients with peptic ulcer hemorrhage have been highlighted by several retrospective studies [170-172]. In the first study, a total of 1920 patients with peptic ulcer hemorrhage were classified into two groups depending on the time of initial eradication therapy administration after ulcer diagnosis. Results revealed that the late eradication group (with late being defined as a time lag $\geq 120$ days after initial diagnosis) had an increased risk of re-hospitalization due to complicated recurrent ulcer compared to patients receiving earlier eradication therapy $(\mathrm{HR} 1.52,95 \% \mathrm{Cl} 1.13-2.04 ; P=$ $0.006)$ [170]. Another study of 830 peptic ulcer hemorrhage patients similarly displayed that adherence to the recommended $H$. pylori testing strategy (endoscopic biopsy, stool antigen testing or serology for $H$. pylori within 60 days of index endoscopy) correlated with a lower risk of hospital ICU admission ( $90 \%$ of non-ICU patients tested vs. $66 \%$ of ICU patients, $P<$ 0.001 ; adjusted OR $0.42,95 \% \mathrm{Cl} 0.27-0.66$ ) and a decreased compound risk of rebleeding or mortality 14-365 days after 
index endoscopy ( $22 \%$ vs. $47 \%, P<0.01$; adjusted HR 0.49 , $95 \%$ Cl 0.36-0.67) [171]. However, delay in initiation of H. pylori eradication therapy, starting even from 8-30 days after peptic ulcer diagnosis, may time-dependently increase the risks of recurrence and development of a complicated ulcer, as shown by a nationwide population-based study including 29032 patients [172]. Initiation of eradication therapy within 8-30, 31-60, 61365 , and $>365$ days of diagnosis was compared to immediate treatment within 7 days. Adjusted HRs for ulcer recurrence were 1.17 (95\%Cl 1.08-1.25), 2.37 (95\%Cl 2.16-2.59), 2.96 (95\%Cl 2.76-3.16), and 3.55 (95\%Cl 3.33-3.79), respectively, while HRs for complicated ulcer were 1.55 (95\% Cl 1.35-1.78), $3.19(95 \% \mathrm{Cl} 2.69-3.78), 4.00(95 \% \mathrm{Cl} 3.51-4.55)$, and 6.14 (95\% $\mathrm{Cl}$ 5.47-6.89), respectively. These results reaffirm the current view that testing for $H$. pylori and subsequent initiation of eradication therapy in the case of detection, should be performed as soon as possible in all patients presenting with acute NVUGIH secondary to peptic ulcer.

The higher rates of false-negative results linked to $\mathrm{H}$. pylori testing in the acute setting (at index endoscopy) of NVUGIH constitutes an obstacle to the implementation of this testing strategy [173]. It is therefore advisable to repeat diagnostic testing in patients with an initially negative $H$. pylori test, within 4 weeks of the acute bleeding episode [174]. Interestingly, no recent meta-analyses or RCTs further examining either the diagnostic performance of testing in the acute setting or the concept of re-testing after the bleeding event, have been published. Re-testing for $\mathrm{H}$. pylori is further supported only by the results of a 2014 prospective cohort study including 374 patients, in which retesting provided an additional diagnostic yield of $12.5 \%$ (11 patients newly positive during delayed testing out of 88 initially negative patients, who repeated testing either through endoscopy or urea breath testing) [175]. Nevertheless, current evidence substantively justifies both the value of $H$. pylori testing in the acute setting as well as the role of delayed testing in minimizing the underestimation of $\mathrm{H}$. pylori prevalence in peptic ulcer hemorrhage.

\section{Dual antiplatelet therapy and PPI co-therapy}

\section{RECOMMENDATION}

ESGE recommends that in patients who have had acute NVUGIH and require ongoing dual antiplatelet therapy (DAPT), PPI should be given as co-therapy.

Strong recommendation, moderate quality evidence.

Dual antiplatelet therapy (DAPT), combining low dose aspirin and a P2Y12 platelet receptor inhibitor (e.g., clopidogrel), is the cornerstone of management of patients with acute coronary syndromes and following coronary stent placement, but is associated with an increased risk of Gl bleeding. PPIs substantially reduce this risk and their use as co-therapy with DAPT is recommended in patients with a previous GI bleeding event [1,176-178]. Previous pharmacodynamic studies reported that the co-administration of PPIs with clopidogrel may reduce platelet inhibition, yet there is no high level evidence support- ing the clinical significance of this interaction [179-181]. A recent meta-analysis again showed no significant difference between patients using clopidogrel alone and patients receiving the combination of clopidogrel and a PPI $(n=11770)$, for allcause mortality (OR $0.91,95 \% \mathrm{Cl} 0.58-1.40 ; P=0.66$ ), acute coronary syndrome (OR $0.96,95 \% \mathrm{Cl} 0.88-1.05$; $P=0.35)$, myocardial infarction (OR 1.05, 95\%Cl 0.86-1.28; $P=0.65$ ), or cerebrovascular accident (OR 1.47, $95 \% \mathrm{Cl} 0.660-3.25 ; P=0.34$ ) [182]. Moreover, the incidence of GI bleeding was significantly decreased in the group of patients who received PPI co-therapy (OR 0.24, $95 \%$ Cl 0.09-0.62; $P=0.003$ ).

\section{Restarting anticoagulation therapy (VKAs, DOACs)}

\section{RECOMMENDATION}

ESGE recommends that, in patients who require ongoing anticoagulation therapy following acute NVUGIH (e.g., peptic ulcer hemorrhage), anticoagulation should be resumed as soon as the bleeding has been controlled, preferably within or soon after 7 days of the bleeding event, based on thromboembolic risk. The rapid onset of action of direct oral anticoagulants (DOACs), as compared to vitamin $\mathrm{K}$ antagonists (VKAs), must be considered in this context.

Strong recommendation, low quality evidence.

\section{RECOMMENDATION}

ESGE recommends PPIs for gastroduodenal prophylaxis in patients requiring ongoing anticoagulation and with a history of NVUGIH.

Strong recommendation, low quality evidence.

There is only limited evidence to guide restarting anticoagulation therapy (e.g., VKAs, DOACs) following NVUGIH (e.g., peptic ulcer hemorrhage). The decision to restart anticoagulation therapy must balance the risk of recurrent bleeding with the risk of a thromboembolic event and/or the sequelae of these events, including death. Retrospective, observational studies have shown that resuming anticoagulation in patients following a GI bleed is associated with a lower risk of thrombosis and death [183-185] but a small increase in nonfatal Gl bleeding events $[34,186]$. Sostres et al. reported on 871 patients with Gl bleeding, 25\% with peptic ulcer hemorrhage, while taking antithrombotic medications (38.9\% anticoagulants, $52.5 \%$ antiplatelets, and $8.6 \%$ both) [34]. Over an extended follow-up period (mean 24.9 months), the authors concluded that resumption of either antiplatelet or anticoagulant therapy (mean [standard deviation] 7.3 [5.9] days, median 5 days) was associated with a higher risk of rebleeding, yet a lower risk of ischemic events or death. Moreover, when compared to late resumption, earlier resumption of antithrombotic therapy ( $\leq 7$ days) following the Gl bleeding episode, was associated with a significantly lower rate of ischemic events (13.6\% vs. $20.4 \%, P=0.025$; adjusted HR $0.718,95 \% \mathrm{Cl} 0.487-1.061$ ) and 
a significantly higher rate of recurrent Gl bleeding (30.6\% vs. $23.1 \%, P=0.044$; adjusted $\mathrm{HR} 1.383,95 \% \mathrm{Cl} 1.001-1.910)$. A systematic review suggested that anticoagulation can be restarted between 7 and 15 days following the Gl bleed event [187]. A risk modelling analysis, based on 121/207 patients (58.5\%) who restarted VKAs after an upper GI bleed, suggested that the optimal timing for the resumption of anticoagulation appears to be between 3-6 weeks after the index bleeding event, but that the decision must take into account thromboembolic risk and patient values and preferences [188]. In patients at high thrombotic risk for whom early resumption of anticoagulation within the first week following an acute bleeding event may be appropriate, bridging therapy using unfractionated or low molecular weight heparin should be considered. (Patients at high thrombotic risk include those with chronic atrial fibrillation with a previous embolic event; CHADS2 $\geq 3$ [risk score including congestive heart failure, hypertension, age $\geq 75$ years, diabetes mellitus, and previous stroke or transient ischemic attack]; mechanical prosthetic heart valve; recent deep venous thrombosis or pulmonary embolism [within past 3 months]; or with known severe hypercoagulable state.) This decision should be multidisciplinary involving a cardiologist and/or a hematologist. VKAs should be restarted earlier, as a loading dose is required and these medications take longer to achieve their anticoagulation effect.

Some experts suggest that a DOAC with less bleeding risk or a VKA with tight INR control should be prescribed. In an observational cohort study on post-hemorrhage anticoagulation resumption in patients with atrial fibrillation, the incidence of major recurrent bleeding was higher for patients on warfarin than for those on dabigatran ( $\mathrm{HR} 2.31,95 \% \mathrm{Cl} 1.19-4.76)$ [189]. In the ARISTOTLE (Apixaban for the Prevention of Stroke in Subjects with Atrial Fibrillation) trial, the rate of major bleeding was $2.13 \%$ per year with the use of apixaban and $3.09 \%$ with that of warfarin (HR $0.69,95 \% \mathrm{Cl} 0.60-0.80 ; P<0.001)$ [190]. However, no firm conclusion can be made as there is no direct comparison of DOACs or warfarin in patients after a major $\mathrm{Gl}$ bleeding event.

The precise timing for restarting anticoagulation in patients who require anticoagulant therapy and who have had acute NVUGIH (e.g., peptic ulcer hemorrhage) remains undefined. However, evidence supports resuming anticoagulation within 7 days, provided that the GI bleeding has been controlled. In this context, clinicians must balance the thrombotic risk with the bleeding risk. Those patients at the highest thrombotic risk should restart anticoagulant therapy as soon as possible and the use of subcutaneous low molecular weight heparin as a bridge to oral anticoagulation may be a good option. Early consultation with a cardiologist and/or hematologist is desirable. It should be remembered that the timing for resumption of VKA is different from that for DOACs. Vitamin K antagonists should be started earlier since the time required to achieve adequate anticoagulation is much longer (up to 5 days) compared to that for DOACs which take only hours. The use of validated clinical prediction scores that estimate thrombotic risk (CHA(2)DS(2)-VASc) and bleeding risk (HAS-BLED) can be used to help guide clinicians in their decision making (> Fig. 2) [191193].

\section{Use of PPI in patients taking anticoagulants}

The evidence for the protective effect of PPI in patients taking anticoagulants is limited. Unlike aspirin, anticoagulants do not cause mucosal breaks or ulcers, but they increase the risk of bleeding from pre-existing mucosal lesions or those induced by other agents or pathogenic mechanisms. Epidemiological studies have reported conflicting results [194-198]. However, we recommend the use of PPI in patients who require ongoing anticoagulation and have a history of previous peptic ulcer hemorrhage. This should be exclusive to patients who need to take anticoagulants and other gastrotoxic drugs such as nonsteroidal anti-inflammatory drugs (NSAIDs) or aspirin [198]. The recent COMPASS (Rivaroxaban for the Prevention of Major Cardiovascular Events in Coronary or Peripheral Artery Disease) trial suggested that PPIs do not prevent gastrointestinal bleeding in patients receiving anticoagulants [199]. Patients with stable cardiovascular diseases were randomized to receive rivaroxaban ( $2.5 \mathrm{mg}$ twice-daily) plus aspirin (100 mg once-daily), or rivaroxaban ( $5 \mathrm{mg}$ twice daily) with an aspirin-matched placebo once-daily, or aspirin (100 mg once-daily) with a rivaroxaban-matched placebo (twice-daily). These patients were then further randomized to receive $40 \mathrm{mg}$ pantoprazole or a placebo. There was no significant difference in upper Gl events between the pantoprazole group $102 / 8791$ (1.2\%) and the placebo group $116 / 8807$ (1.3\%) (HR 0.88, $95 \% \mathrm{Cl} 0.67-1.15)$. However, there were fewer occurrences of symptomatic gastroduodenal ulcers and acid-peptic related complications with the use of pantoprazole ( 8 vs. 17 ; HR $0.47,95 \% \mathrm{Cl} 0.20-1.09$ ). In a retrospective Chinese cohort study $(n=5041)$, the use of PPI was associated with a reduced risk of Gl bleeding in patients taking dabigatran and only in those with a prior history of peptic ulcer/ Gl bleed (incidence rate ratio [IRR] $0.14,95 \% \mathrm{Cl} 0.06-0.30$ ) [200]. Risk factors for developing GI bleeding were patient age of 75 years or older, history of peptic ulcer/Gl bleed and concomitant use of aspirin.

\section{Disclaimer}

The legal disclaimer for ESGE guidelines [4] applies to this Guideline.

\section{Acknowledgments}

ESGE wishes to thank external reviewers, Professor Alan N. Barkun of McGill University, Montreal, Canada, and Professor Philip Chiu of The Chinese University of Hong Kong for their critical review and appraisal of this guideline.

\section{Competing interests}

N. de Groot has worked with the NUMDL group on a national guideline on Gl bleeding (January to June 2017). M. Dinis-Ribeiro has provided consultancy to Medtronic (October 2020); he is a Co-Editor-in-Chief of the journal Endoscopy. I.M. Gralnek is a consultant to Boston Scien- 
tific, Medtronic, Motus GI, Vifor Pharma, Simbionix, and Neurogastrx; he is also on the medical advisory board of Motus $\mathrm{Gl}$ and has received research funding from them and from OnePass, AstraZeneca and CheckCap; he has also been a speaker for Vifor Pharma and 3D Matrix. A. Lanas has provided consultancy to Bayer AG (2018 to 2020). A.J. Morris serves on an advisory board for Medtronic (October 2020, ongoing); he is an unpaid committee member and a guideline lead for the British Society of Gastroenterology (BSG); he has received a fee for a commissioned article in Medicine International journal (2019). I.S. Papanikolaou has received a consultancy fee from Boston Scientific (25 January 2018 and 21 October 2018); he has received travel grants from Takeda Hellas (10-13 October 2019 and 3-6 December 2020). F. Radaelli has served on an advisory board and been a speaker for Pfizer/BMS (2019 to 2020); he has been a speaker for Boehringer Ingelheim (2019 to 2020). A. Sanchez-Yague has received consultancy fees from Boston Scientific (2017 to 2019). J.E. van Hooft has received lecture fees from Medtronic (2014 to 2015, 2019) and Cook Medical (2019), and consultancy fees from Boston Scientific (2014 to 2017); her department has received research grants from Cook Medical (2014 to 2019), and Abbott (2014 to 2017). H. Awadie, G. Braun, M. Camus, T. Cúrdia Gonçalves, J. Lau, S.B. Laursen, Z. Neeman, A.J. Stanley, and M. Udd declare no competing interests.

\section{References}

[1] Oakland K. Changing epidemiology and etiology of upper and lower gastrointestinal bleeding. Best Pract Res Clin Gastroenterol 2019; 42/ 43: 1-6

[2] Gralnek IM, Dumonceau JM, Kuipers E] et al. Diagnosis and management of nonvariceal upper gastrointestinal hemorrhage: European Society of Gastrointestinal Endoscopy (ESGE) Guideline. Endoscopy 2015; 47: 1-46

[3] Guyatt GH, Oxman AD, Vist GE et al. GRADE: an emerging consensus on rating quality of evidence and strength of recommendations. BM] 2008; 336: 924-926

[4] Hassan C, Ponchon T, Bisschops R et al. European Society of Gastrointestinal Endoscopy (ESGE) Publications Policy - Update 2020. Endoscopy 2020; 52: 123-126

[5] Baradarian R, Ramdhaney S, Chapalamadugu R et al. Early intensive resuscitation of patients with upper gastrointestinal bleeding decreases mortality. Am J Gastroenterol 2004; 99: 619-622

[6] Lu B, Li MQ, Li JQ. The use of limited fluid resuscitation and blood pressure-controlling drugs in the treatment of acute upper gastrointestinal hemorrhage concomitant with hemorrhagic shock. Cell Biochem Biophys 2015; 72: 461-463

[7] Kwan I, Bunn F, Chinnock P et al. Timing and volume of fluid administration for patients with bleeding. Cochrane Database Syst Rev 2014: CD002245

[8] Duan C, Li T, Liu L. Efficacy of limited fluid resuscitation in patients with hemorrhagic shock: a meta-analysis. Int J Clin Exp Med 2015; 8: 11645-11656

[9] Carrick MM, Morrison CA, Tapia NM et al. Intraoperative hypotensive resuscitation for patients undergoing laparotomy or thoracotomy for trauma: Early termination of a randomized prospective clinical trial. J Trauma Acute Care Surg 2016; 80: 886-896

[10] Lewis SR, Pritchard MW, Evans D] et al. Colloids versus crystalloids for fluid resuscitation in critically ill people. Cochrane Database Syst Rev 2018; 8: CD000567

[11] Hammond DA, Lam SW, Rech MA et al. Balanced crystalloids versus saline in critically ill adults: a systematic review and meta-analysis. Ann Pharmacother 2020; 54: 5-13
[12] Semler MW, Self WH, Wanderer JP et al. Balanced crystalloids versus saline in critically ill adults. N Engl J Med 2018; 378: 829-839

[13] Villanueva C, Colomo A, Bosch A et al. Transfusion strategies for acute upper gastrointestinal bleeding. N Engl J Med 2013; 368: 11-21

[14] Jairath V, Kahan BC, Gray A et al. Restrictive versus liberal blood transfusion for acute upper gastrointestinal bleeding (TRIGGER): a pragmatic, open-label, cluster randomised feasibility trial. Lancet Lond Engl 2015; 386: 137-144

[15] Barkun AN, Almadi M, Kuipers EJ et al. Management of nonvariceal upper gastrointestinal bleeding: guideline recommendations from the international consensus group. Ann Intern Med 2019; 171: 805822

[16] Odutayo A, Desborough MJR, Trivella M et al. Restrictive versus liberal blood transfusion for gastrointestinal bleeding: a systematic review and meta-analysis of randomised controlled trials. Lancet Gastroenterol Hepatol 2017; 2: 354-360

[17] Carson JL, Stanworth S], Roubinian N et al. Transfusion thresholds and other strategies for guiding allogeneic red blood cell transfusion. Cochrane Database Syst Rev 2016; 10: CD002042

[18] Docherty AB, O’Donnell R, Brunskill S et al. Effect of restrictive versus liberal transfusion strategies on outcomes in patients with cardiovascular disease in a non-cardiac surgery setting: systematic review and meta-analysis. BMJ 2016; 352: i1351

[19] Blatchford O, Murray WR, Blatchford M. A risk score to predict need for treatment for upper-gastrointestinal haemorrhage. Lancet 2000; 356: 1318-1321

[20] Rockall TA, Logan RF, Devlin HB et al. Risk assessment after acute upper gastrointestinal haemorrhage. Gut 1996; 38: 316-321

[21] Saltzman JR, Tabak YP, Hyett BH et al. A simple risk score accurately predicts in-hospital mortality, length of stay, and cost in acute upper Gl bleeding. Gastrointest Endosc 2011; 74: 1215-1224

[22] Laursen SB, Dalton HR, Murray IA et al. Performance of new thresholds of the Glasgow Blatchford score in managing patients with upper gastrointestinal bleeding. Clin Gastroenterol Hepatol 2015; 13: 115121

[23] Ramaekers R, Mukarram M, Smith CAM et al. The predictive value of pre-endoscopic risk scores to predict adverse outcomes in emergency department patients with upper gastrointestinal bleeding: a systematic review. Acad Emerg Med 2016; 23: 1218-1227

[24] Stanley AJ, Laine L, Dalton HR et al. International gastrointestinal bleeding consortium. comparison of risk scoring systems for patients presenting with upper gastrointestinal bleeding: international multicentre prospective study. BMJ 2017; 356: i6432

[25] Stanley AJ, Ashley D, Dalton HR et al. Outpatient management of patients with low-risk upper-gastrointestinal haemorrhage: multicentre validation and prospective evaluation. Lancet 2009; 373: 42-47

[26] Girardin M, Bertolini D, Ditisheim S et al. Use of Glasgow-Blatchford bleeding score reduces hospital stay duration and costs for patients with low-risk upper GI bleeding. Endosc Int Open 2014; 2: E74-E79

[27] Sung JJY, Lau JYW, Ching JYL et al. Continuation of low dose aspirin therapy in peptic ulcer bleeding: a randomized trial. Ann Intern Med 2010; 152: 1-9

[28] Derogar M, Sandblom G, Lundell L et al. Discontinuation of low dose aspirin therapy after peptic ulcer bleeding increases risk of death and acute cardiovascular events. Clin Gastroenterol Hepatol 2013; 11: $38-42$

[29] Kim SY, Hyun J], Suh S] et al. Risk of vascular thrombotic events following discontinuation of anti-thrombotics after peptic ulcer bleeding. J Clin Gastroenterol 2016; 50: e40-e44 
[30] Wang XX, Dong B, Hong B et al. Long-term prognosis in patients continuing taking anti-thrombotics after peptic ulcer bleeding. World J Gastroenterol 2017; 23: 723-729

[31] Siau K, Hannah JL, Hodson J et al. Stopping antithrombotic therapy after acute upper gastrointestinal bleeding is associated with reduced survival. Postgrad Med J 2018; 94: 137-142

[32] Burger W, Chemnitius JM, Kneissl GD et al. Low-dose aspirin for secondary cardiovascular prevention - cardiovascular risks after its perioperative withdrawal versus bleeding risks with its continuation - review and meta-analysis. J Intern Med 2005; 257: 399-414

[33] Sung J], Chiu PW, Chan FKL et al. Asia-Pacific working group consensus on non-variceal upper gastrointestinal bleeding: an update 2018. Gut 2018; 67: 1757-1768

[34] Sostres C, Marcén B, Laredo V et al. Risk of rebleeding, vascular events and death after gastrointestinal bleeding in anticoagulant and/or antiplatelet users. Aliment Pharmacol Ther 2019; 50: 919-929

[35] Patrono C, Morais J, Baigent $C$ et al. Antiplatelet agents for the treatment and prevention of coronary atherothrombosis. J Am Coll Cardiol 2017; 70: 1760-1776

[36] Eisenberg MJ, Richard PR, Libersan D et al. Safety of short-term discontinuation of antiplatelet therapy in patients with drug-eluting stents. Circulation 2009; 119: 1634-42

[37] Ramos GP, Binder M, Hampel P et al. Outcomes of endoscopic intervention for overt Gl bleeding in severe thrombocytopenia. Gastrointest Endosc 2018; 88: 55-61

[38] Zakko L, Rustagi T, Douglas M et al. No benefit from platelet transfusion for gastrointestinal bleeding in patients taking antiplatelet agents. Clin Gastroenterol Hepatol 2017; 15: 46-52

[39] Bennett C, Klingenberg SL, Langholz E, Gluud LL. Tranexamic acid for upper gastrointestinal bleeding. Cochrane Database of Systematic Reviews 2014; 11: doi:10.1002/14651858.CD006640.pub3

[40] Stollings JL, Landsperger JS, Semler MW et al. Tranexamic acid for refractory gastrointestinal bleeds: A cohort study. J Crit Care 2018; 43 : $128-132$

[41] Tavakoli N, Mokhtare M, Agah S et al. Comparison of the efficacy of intravenous tranexamic acid with and without topical administration versus placebo in urgent endoscopy rate for acute gastrointestinal bleeding: A double-blind randomized controlled trial. United European Gastroenterol J 2018: 646-654

[42] Twum-Barimah E, Abdelgadir I, Gordon M et al. Systematic review with meta-analysis: the efficacy of tranexamic acid in upper gastrointestinal bleeding. Aliment Pharmacol Ther 2020; 51: 1004-1013

[43] Roberts I, Shakur-Still H, Afolabi A et al. Effects of a high-dose 24-h infusion of tranexamic acid on death and thromboembolic events in patients with acute gastrointestinal bleeding (HALT-IT): an international randomised, double-blind, placebo-controlled trial. Lancet 2020; 395: 1927-1936

[44] Lanas A, Dumonceau JM, Hunt RH et al. Non-variceal upper gastrointestinal bleeding. Nat Rev Dis Primers 2018; 4: 18020 doi:10.1038/ nrdp. 2018.20

[45] Lanas-Gimeno A, Lanas A. Risk of gastrointestinal bleeding during anticoagulant treatment. Expert Opin Drug Saf 2017; 16: 673-685

[46] Choudari CP, Rajgopal C, Palmer KR. Acute gastrointestinal haemorrhage in anticoagulated patients: diagnoses and response to endoscopic treatment. Gut 1994; 35: 464-466

[47] Rubin TA, Murdoch M, Nelson DB. Acute Gl bleeding in the setting of supratherapeutic international normalized ratio in patients taking warfarin: endoscopic diagnosis, clinical management, and outcomes. Gastrointest Endosc 2003; 58: 369-373
[48] Wolf AT, Wasan SK, Saltzman JR. Impact of anticoagulation on rebleeding following endoscopic therapy for nonvariceal upper gastrointestinal hemorrhage. Am J Gastroenterol 2007; 102: 290-296

[49] Nagata N, Sakurai T, Moriyasu S et al. Impact of INR monitoring, reversal agent use, heparin bridging, and anticoagulant interruption on rebleeding and thromboembolism in acute gastrointestinal bleeding. PLoS One 2017; 12: e0183423

[50] Sarode R, Milling TJJr., Refaai MA et al. Efficacy and safety of a 4-factor prothrombin complex concentrate in patients on vitamin $\mathrm{K}$ antagonists presenting with major bleeding: a randomized, plasma-controlled, phase IIIb study. Circulation 2013; 128: 1234-1243

[51] Goldstein JN, Refaai MA, Milling TJJr. et al. Four-factor prothrombin complex concentrate versus plasma for rapid vitamin $\mathrm{K}$ antagonist reversal in patients needing urgent surgical or invasive interventions: a phase $3 b$, open-label, non-inferiority, randomised trial. Lancet 2015; 385: 2077-2087

[52] Shim CN, Chung HS, Park JC et al. Is endoscopic therapy safe for upper gastrointestinal bleeding in anticoagulated patients with supratherapeutic international normalized ratios? Am J Ther 2016; 23: e995e1003

[53] Peloquin JM, Seraj SM, King LY et al. Diagnostic and therapeutic yield of endoscopy in patients with elevated INR and gastrointestinal bleeding. Am J Med 2016; 129: 628-634

[54] Holbrook A, Schulman S, Witt DM et al. Evidence-based management of anticoagulant therapy: Antithrombotic therapy and prevention of thrombosis, 9th ed: American College of Chest Physicians EvidenceBased Clinical Practice Guidelines. Chest 2012; 141: e152S-184S

[55] Sin JH, Berger K, Lesch CA. Four-factor prothrombin complex concentrate for life-threatening bleeds or emergent surgery: A retrospective evaluation. J Crit Care 2016; 36: 166-172

[56] Subramaniam K, Spilsbury K, Ayonrinde OT et al. Red blood cell transfusion is associated with further bleeding and fresh-frozen plasma with mortality in nonvariceal upper gastrointestinal bleeding. Transfusion 2016; 56: 816-826

[57] Fabricius R, Svenningsen P, Hillingsø J et al. Effect of transfusion strategy in acute non-variceal upper gastrointestinal bleeding: a nationwide study of 5861 hospital admissions in Denmark. World J Surg 2016; 40: 1129-36

[58] Karaca MA, Erbil B, Ozmen MM. Use and effectiveness of prothrombin complex concentrates vs fresh frozen plasma in gastrointestinal hemorrhage due to warfarin usage in the ED. Am J Emerg Med 2014; 32: 660-664

[59] Zatta A, McQuilten Z, Kandane-Rathnayake R et al. The Australian and New Zealand Haemostasis Registry: ten years of data on off-licence use of recombinant activated factor VII. Blood Transfus 2015; 13: 8699

[60] Liesenfeld KH, Gruenenfelder F, Clemens A. Enhanced elimination of dabigatran: Identifying the appropriate patient for the use of continuous venovenous hemodialysis instead of intermittent hemodialysis A simulation analysis. J Clin Pharmacol 2016; 56: 597-608

[61] Dager WE, Banares L. Reversing the anticoagulation effects of dabigatran. Hosp Pract 2017; 45: 29-38

[62] Schulman S, Ritchie B, Nahirniak S et al. Reversal of dabigatranassociated major bleeding with activated prothrombin concentrate: A prospective cohort study. Thromb Res 2017; 152: 44-48

[63] Pollack CV, Reilly PA, van Ryn J et al. Idarucizumab for dabigatran reversal - full cohort analysis. N Engl J Med 2017; 377: 431-441

[64] Deutsch D, Boustiere C, Ferrari E et al. Direct oral anticoagulants and digestive bleeding: therapeutic management and preventive measures. Therap Adv Gastroenterol 2017; 10: 495-505

[65] Heidbuchel H, Verhamme P, Alings $M$ et al. Updated European Heart Rhythm Association practical guide on the use of non-vitamin-K antagonist anticoagulants in patients with non-valvular atrial fibrillation: Executive summary. Eur Heart J 2017; 38: 2137-2149 
[66] Connolly S], Milling T], Eikelboom JW et al. Andexanet alfa for acute major bleeding associated with factor Xa inhibitors. N Engl J Med 2016; 375: 1131-1141

[67] Ansell JE, Bakhru SH, Laulicht BE et al. Single-dose ciraparantag safely and completely reverses anticoagulant effects of edoxaban. Thromb Haemost 2017; 117: 238-245

[68] Sreedharan A, Martin J, Leontiadis Gl et al. Proton pump inhibitor treatment initiated prior to endoscopic diagnosis in upper gastrointestinal bleeding. Cochrane Database Syst Rev 2010; 7: CD005415

[69] Barkun AN, Bardou M, Kuipers E] et al. International consensus recommendations on the management of patients with nonvariceal upper gastrointestinal bleeding. Ann Intern Med 2010; 152: 101-13

[70] Siau K, Hearnshaw S, Stanley A] et al. British Society of Gastroenterology (BSG)-led Multisociety consensus care bundle for the early clinical management of acute upper gastrointestinal bleeding. Frontline Gastroenterol 2020; 11: 311-323

[71] Raptis S, Dollinger HC, von Berger L et al. Effects of somatostatin on gastric secretion and gastrin release in man. Digestion 1975; 13: 1526

[72] Riha HM, Wilkinson R, Twilla J et al. Octreotide added to a proton pump inhibitor versus a proton pump inhibitor alone in nonvariceal upper-gastrointestinal bleeds. Ann Pharmacother 2019; 53: 794-800

[73] Kessel B, Olsha O, Younis A et al. Evaluation of nasogastric tubes to enable differentiation between upper and lower gastrointestinal bleeding in unselected patients with melena. Eur J Emerg Med 2016; 23: 71-73

[74] Machlab S, Garcia-Iglesias P, Martinez-Bauer E et al. Diagnostic utility of nasogastric tube aspiration and the ratio of blood urea nitrogen to creatinine for distinguishing upper and lower gastrointestinal tract bleeding. Emergencias 2018; 30: 419-423

[75] Rockey DC, Ahn C, de Melo SW. Randomized pragmatic trial of nasogastric tube placement in patients with upper gastrointestinal tract bleeding. J Investig Med 2017; 65: 759-764

[76] Chaudhuri D, Bishay K, Tandon P et al. Prophylactic endotracheal intubation in critically ill patients with upper gastrointestinal bleed: a systematic review and meta-analysis. JGH Open 2019: doi:10.1002/ jgh3.12195

[77] Alshamsi F, Jaeschke R, Baw B et al. Prophylactic endotracheal intubation in patients with upper gastrointestinal bleeding undergoing endoscopy: a systematic review and meta-analysis. Saudi J Med Med Sci 2017; 5: 201-209

[78] Almashhrawi AA, Rahman R, Jersak ST et al. Prophylactic tracheal intubation for upper Gl bleeding: a meta-analysis. World J Metaanal 2015; 3: 4-10

[79] Perisetti A, Kopel J, Shredi A et al. Prophylactic pre-esophagogastroduodenoscopy tracheal intubation in patients with upper gastrointestinal bleeding. Proc (Bayl Univ Med Cent) 2019; 32: 22-25

[80] Enestvedt BK, Gralnek IM, Mattek N et al. An evaluation of endoscopic indications and findings related to non-variceal upper-GI hemorrhage in a large multicenter consortium. Gastrointest Endosc 2008; 67: 422-429

[81] Hearnshaw SA, Logan RF, Lowe D et al. Use of endoscopy for management of acute upper gastrointestinal bleeding in the UK: results of a nationwide audit. Gut 2010; 59: 1022-1029

[82] Bai Y, Guo JF, Li ZS. Meta-analysis: erythromycin before endoscopy for acute upper gastrointestinal bleeding. Aliment Pharmacol Ther 2011; 34: $166-171$

[83] Szary NM, Gupta R, Choudhary A et al. Erythromycin prior to endoscopy in acute upper gastrointestinal bleeding: a meta-analysis. Scand J Gastroenterol 2011; 46: 920-924

[84] Theivanayagam S, Lim RG, Cobell WJ et al. Administration of erythromycin before endoscopy in upper gastrointestinal bleeding: a meta- analysis of randomized controlled trials. Saudi J Gastroenterol 2013; 19: $205-210$

[85] Barkun AN, Bardou M, Martel M et al. Prokinetics in acute upper GI bleeding: a meta-analysis. Gastrointest Endosc 2010; 72: 1138-1145

[86] Rahman R, Nguyen DL, Sohail U et al. Pre-endoscopic erythromycin administration in upper gastrointestinal bleeding: an updated metaanalysis and systematic review. Ann Gastroenterol 2016; 29: 312-317

[87] Winstead NS, Wilcox CM. Erythromycin prior to endoscopy for acute upper gastrointestinal haemorrhage: a cost-effectiveness analysis. Aliment Pharmacol Ther 2007; 26: 1371-1377

[88] Gomes T, Mamdani MM, Juurlink DN. Macrolide-induced digoxin toxicity: a population-based study. Clin Pharmacol Ther 2009; 86: 383-386

[89] Rowan C, Brinker AD, Nourjah P et al. Rhabdomyolysis reports show interaction between simvastatin and CYP3A4 inhibitors. Pharmacoepidemiol Drug Saf 2009; 18: 301-309

[90] Alexandrino G, Domingues TD, Carvalho R et al. Endoscopy in patients with acute upper gastrointestinal bleeding. Clin Endosc 2019; 52: 47 52

[91] Ahn DW, Park YS, Lee SH et al. Clinical outcome of acute nonvariceal upper gastrointestinal bleeding after hours: the role of urgent endoscopy. Korean J Intern Med 2016; 31: 470-478

[92] Garg SK, Anugwom C, Campbell ] et al. Early esophagogastroduodenoscopy in upper gastrointestinal bleeding: a nationwide study. Endosc Int Open 2017; 5: E376-E386

[93] Siau K, Hodson J, Ingram R et al. Time to endoscopy for acute upper gastrointestinal bleeding: results from a prospective multicentre trainee-led audit. United European Gastroenterol J 2019; 7: 199-209

[94] Jeong N, Kim KS, Jung YS et al. Delayed endoscopy is associated with increased mortality in upper gastrointestinal hemorrhage. Am J Emerg Med 2019; 37: 277-280

[95] Xia XF, Chiu PWY, Tsoi KKF et al. The effect of off-hours hospital admission on mortality and clinical outcomes for patients with upper gastrointestinal hemorrhage: a systematic review and meta-analysis of 20 cohorts. United European Gastroenterol J 2018; 6: 367-381

[96] Cho SH, Lee YS, Kim YJ et al. Outcomes and role of urgent endoscopy in high-risk patients with acute nonvariceal gastrointestinal bleeding. Clin Gastroenterol Hepatol 2018; 16: 370-377

[97] Kumar NL, Cohen AJ, Nayor J et al. Timing of upper endoscopy influences outcomes in patients with acute nonvariceal upper GI bleeding. Gastrointest Endosc 2017; 85: 945-952

[98] Lau JYW, Yu Y, Tang RSY et al. Timing of endoscopy for acute upper gastrointestinal bleeding. N Engl J Med 2020; 382: 1299-1308

[99] Laursen SB, Leontiadis GI, Stanley AJ et al. Relationship between timing of endoscopy and mortality in patients with peptic ulcer bleeding: a nationwide cohort study. Gastrointest Endosc 2017; 85: 936-944

[100] Matsuura S, Sakata Y, Tsuruoka N et al. Outcomes of patients undergoing endoscopic hemostasis for the upper gastrointestinal bleeding were not influenced by the hospital emergency visits: a situation prevailing in Japan. Digestion 2018; 97: 260-266

[101] Shih P, Liu S, Li S et al. Weekend effect in upper gastrointestinal bleeding: a systematic review and meta-analysis. Peer] 2018; 6: e428

[102] Forrest JA, Finlayson ND, Shearman DJ. Endoscopy in gastrointestina bleeding. Lancet 1974; 2: 394-397

[103] Elmunzer BJ, Young SD, Inadomi JM et al. Systematic review of the predictors of recurrent hemorrhage after endoscopic hemostatic therapy for bleeding peptic ulcers. Am J Gastroenterol 2008; 103: 2625-2632

[104] Lau JY, Sung JJ, Chan AC et al. Stigmata of hemorrhage in bleeding peptic ulcers: an interobserver agreement study among international experts. Gastrointest Endosc 1997; 46: 33-36 
[105] Mondardini A, Barletti C, Rocca G et al. Non-variceal upper gastrointestinal bleeding and Forrest's classification: diagnostic agreement between endoscopists from the same area. Endoscopy 1998; 30: 508-512

[106] Jensen DM, Eklund S, Persson T et al. Reassessment of rebleeding risk of Forrest IB (oozing) peptic ulcer bleeding in a large international randomized trial. Am J Gastroenterol 2017; 112: 441-446

[107] Jensen DM, Ohning GV, Kovacs TO et al. Doppler endoscopic probe as a guide to risk stratification and definitive hemostasis of peptic ulcer bleeding. Gastrointest Endosc 2016; 83: 129-136

[108] Camus M, Jensen DM, Kovacs TO et al. Independent risk factors of 30-day outcomes in 1,264 patients with peptic ulcer bleeding in the USA: large ulcers do worse. Aliment Pharmacol Ther 2016; 43: 1080-1089

[109] Lolle I, Møller MH, Rosenstock S]. Association between ulcer site and outcome in complicated peptic ulcer disease: a Danish nationwide cohort study. Scand J Gastroenterol 2016; 51: 1165-1171

[110] Wong RC, Chak A, Kobayashi K et al. Role of Doppler US in acute peptic ulcer hemorrhage: can it predict failure of endoscopic therapy? Gastrointest Endosc 2000; 52: 315-321

[111] Jensen DM, Kovacs TOG, Ohning GV et al. Doppler endoscopic probe monitoring of blood flow improves risk stratification and outcomes of patients with severe nonvariceal upper gastrointestinal hemorrhage. Gastroenterology 2017; 152: 1310-1318

[112] Kantowski M, Schoepfer AM, Settmacher U et al. Assessment of endoscopic doppler to guide hemostasis in high risk peptic ulcer bleeding. Scand J Gastroenterol 2018; 53: 1311-1318

[113] Barkun AN, Adam V, Wong RCK. Use of doppler probe in nonvariceal upper-gastrointestinal bleeding is less costly and more effective than standard of care. Clin Gastroenterol Hepatol 2019; 17: 24632470

[114] Marya NB, Jawaid S, Foley A et al. A randomized controlled trial comparing efficacy of early video capsule endoscopy with standard of care in the approach to non-hematemesis GI bleeding (with videos). Gastrointest Endosc 2019; 89: 33-43

[115] Pérez-Cuadrado Robles EE, Bebia Conesa P, Esteban Delgado P et al. Emergency double-balloon enteroscopy combined with real-time viewing of capsule endoscopy: A feasible combined approach in acute overt-obscure gastrointestinal bleeding? Dig Endosc 2015; 27: $338-344$

[116] Schlag C, Menzel C, Nennstiel S et al. Emergency video capsule endoscopy in patients with acute severe Gl bleeding and negative upper endoscopy results. Gastrointest Endosc 2015; 81: 889-895

[117] Ching H, Hale MF, Sidhu R et al. Magnetically assisted capsule endoscopy in suspected acute upper $\mathrm{Gl}$ bleeding versus esophagogastroduodenoscopy in detecting focal lesions. Gastrointest Endosc 2019; 90: 430-439

[118] Schmidt A, Zimmermann M, Bauder M et al. Novel telemetric sensor capsule for EGD urgency triage: a feasibility study. Endosc Int Open 2019; 07: E774-E781

[119] Laine L, McQuaid KR. Endoscopic therapy for bleeding ulcers: an evidence-based approach based on meta-analyses of randomized controlled trials. Clin Gastroenterol Hepatol 2009; 7: 33-47

[120] Barkun AN, Martel M, Toubouti Y et al. Endoscopic hemostasis in peptic ulcer bleeding for patients with high-risk lesions: a series of meta-analyses. Gastrointest Endosc 2009; 69: 786-799

[121] Sung J], Tsoi KK, Lai LH et al. Endoscopic clipping versus injection and thermo-coagulation in the treatment of non-variceal upper gastrointestinal bleeding: a meta-analysis. Gut 2007; 56: 1364-1373

[122] Marmo R, Rotondano G, Piscopo R et al. Dual therapy versus monotherapy in the endoscopic treatment of high-risk bleeding ulcers: a meta-analysis of controlled trials. Am J Gastroenterol 2007; 102: 279-289
[123] Vergara M, Bennett C, Calvet X et al. Epinephrine injection versus epinephrine injection and a second endoscopic method in high risk bleeding ulcers. Cochrane Database Syst Rev 2014; 10: CD005584

[124] Baracat F, Moura E, Bernardo W et al. Endoscopic hemostasis for peptic ulcer bleeding: systematic review and meta-analyses of randomized controlled trials. Surg Endosc 2016: 2155-2168

[125] Shi K, Shen Z, Zhu G et al. Systematic review with network metaanalysis: dual therapy for high-risk bleeding peptic ulcers. BMC Gastroenterology 2017; 55: doi:10.1186/s12876-017-0610-0

[126] Kim JW, Jang JY, Lee CK et al. Comparison of hemostatic forceps with soft coagulation versus argon plasma coagulation for bleeding peptic ulcer - a randomized trial. Endoscopy 2015; 47: 680-687

[127] Kyaw M, Tse Y, Ang D et al. Embolization versus surgery for peptic ulcer bleeding after failed endoscopic hemostasis: A meta-analysis. Endoscopy International Open 2014; 2: doi:10.1055/s-00341365235

[128] Beggs AD, Dilworth MP, Powell SL et al. A systematic review of transarterial embolization versus emergency surgery in treatment of major nonvariceal upper gastrointestinal bleeding. Clinical and Experimental Gastroenterology 2014; 7: 93-104

[129] Tarasconi A, Baiocchi G, Pattonieri V et al. Transcatheter arterial embolization versus surgery for refractory non-variceal upper gastrointestinal bleeding: A meta-analysis. World J Emerg Surgery 2014; 14: 1-13

[130] Sverden E, Mattsson F, Lindstrom D et al. Transcatheter arterial embolization compared with surgery for uncontrolled peptic ulcer bleeding. A population-based cohort study. Ann Surg 2019; 269: 304-309

[131] Park JS, Kim HK, Shin YW et al. Novel hemostatic adhesive powder for nonvariceal upper gastrointestinal bleeding. Endosc Int Open 2019; 07: E1763-E1767

[132] Alzoubaidi D, Hussein M, Rusu R et al. Outcomes from an international multicenter registry of patients with acute gastrointestinal bleeding undergoing endoscopic therapy with Hemospray. Dig Endosc 2020; 32: 96-105

[133] Baracat F, Hourneaux de Moura D, Brunaldi V et al. Randomized controlled trial of hemostatic powder versus endoscopic clipping for non-variceal upper gastrointestinal bleeding. Surg Endosc 2020; 34: 317-324

[134] Barkun AN, Adam V, Lu Y et al. Using Hemospray improves the costeffectiveness ratio in the management of upper gastrointestinal nonvariceal bleeding. J Clin Gastroenterol 2018; 52: 36-44

[135] Wedi E, Fischer A, Hochberger J et al. Multicenter evaluation of firstline endoscopic treatment with the OTSC in acute non-variceal upper gastrointestinal bleeding and comparison with the Rockall cohort: the FLETRock study. Surg Endosc 2018; 32: 307-314

[136] Manta R, Galloro G, Mangiafico S et al. First-line endoscopic treatment with over-the-scope clips in patients with either upper or lower gastrointestinal bleeding: a multicenter study. Endosc Int Open 2018; 06: E1317-E1321

[137] Brandler J, Buttar N, Baruah A et al. Efficacy of over-the-scope clips in management of high-risk gastrointestinal bleeding. Clin Gastroenterol Hepatol 2018; 16: 690-696

[138] Chandrasekar VT, Sharma P, Desai M et al. Efficacy and safety of over-the-scope clips for gastrointestinal bleeding: a systematic review and meta-analysis. Endoscopy 2019; 51: 941-949

[139] Goelder S, Messmann H, Neuhaus L et al. Over-the-scope clip in peptic ulcer bleeding: clinical success in primary and secondary treatment and factors associated with treatment failure. Endoscopy International Open 2019; 7: E846-E854 
[140] Kobara H, Hirohito M, Tsutomu M et al. Over-the-scope-clips: A review of 1517 cases over 9 years. J Gastroenterol Hepatol 2019; 34: 22-30

[141] Richter-Schrag HJ, Thimme R, Glatz T et al. First-line endoscopic treatment with over-the-scope clips significantly improves the primary failure and rebleeding rates in high-risk gastrointestinal bleeding: A single-center experience with 100 cases. World J Gastroenterol 2016; 22: 9162-9171

[142] Asokkumar R, Ngu JH, Soetikno R et al. Use of over-the-scope-clip (OTSC) improves outcomes of high-risk adverse outcome (HR-AO) non-variceal upper gastrointestinal bleeding (NVUGIB). Endoscopy International Open 2018; 06: E789-E796

[143] Lamberts R, Halm U, Koch A et al. Use of over-the-scope-clips (OTSC) for hemostasis in gastrointestinal bleeding in patients under antithrombotic therapy. Endosc Int Open 2017; 05: E324-E330

[144] Wedi E, Hochberger J, Gonzalez S et al. One hundred and one overthe-scope-clip applications for severe gastrointestinal bleeding, leaks and fistula. World J Gastroenterol 2016; 22: 1844-1853

[145] Jensen DM, Kovacs TOG, Ghassemi KA et al. Randomized controlled trial of over-the-scope clip as initial treatment of severe non-variceal upper gastrointestinal bleeding. Clin Gastroenterol Hepatol 2020: doi:10.1016/j.cgh.2020.08.046

[146] Schmidt A, Caca K, Goelder S et al. Over-the-scope clips are more effective than standard endoscopic therapy for patients with recurrent bleeding of peptic ulcers. Gastroenterology 2018; 155: 674686

[147] Arima S, Sakata Y, Ogata S et al. Evaluation of hemostasis with soft coagulation using endoscopic hemostatic forceps in comparison with metallic hemoclips for bleeding gastric ulcers: a prospective, randomized trial. J Gastroenterol 2010; 45: 501-505

[148] Kataoka M, Kawai T, Hayama Y et al. Comparison of hemostasis using bipolar hemostatic forceps with hemostasis by endoscopic hemoclipping for nonvariceal upper gastrointestinal bleeding in a prospective non-randomized trial. Surg Endosc 2013; 27: 3035-3038

[149] Nunoue T, Takenaka R, Hori K et al. A randomized trial of monopolar soft-mode coagulation versus heater probe thermocoagulation for peptic ulcer bleeding. J Clin Gastroenterol 2015; 49: 472-476

[150] Kim JW, Jang JY, Lee CK et al. Comparison of hemostatic forceps with soft coagulation versus argon plasma coagulation for bleeding peptic ulcer - a randomized trial. Endoscopy 2015; 47: 680-687

[151] Toka B, Eminler AT, Karacaer C et al. Comparison of monopolar hemostatic forceps with soft coagulation versus hemoclip for peptic ulcer bleeding: a randomized trial (with video). Gastrointest Endosc 2019; 89: 792-802

[152] Neumann I, Letelier LM, Rada G et al. Comparison of different regimens of proton pump inhibitors for acute peptic ulcer bleeding. Cochrane Database Syst Rev 2013; 6: 007999 doi:10.1002/ 14651858.CD007999

[153] Sgourakis G, Chatzidakis G, Poulou A et al. High-dose vs. low-dose proton pump inhibitors post-endoscopic hemostasis in patients with bleeding peptic ulcer. a meta-analysis and meta-regression analysis. Turk J Gastroenterol 2018; 29: 22-31

[154] Sachar H, Vaidya K, Laine L. Intermittent vs continuous proton pump inhibitor therapy for high-risk bleeding ulcers: a systematic review and meta-analysis. JAMA Intern Med 2014; 174: 1755-1762

[155] Javid G, Zargar SA, U-Saif R et al. Comparison of po or IV proton pump inhibitors on 72 -h intragastric $\mathrm{pH}$ in bleeding peptic ulcer. J Gastroenterol Hepatol 2009; 24: 1236-1243

[156] Sung JJ, Suen BY, Wu JC et al. Effects of intravenous and oral esomeprazole in the prevention of recurrent bleeding from peptic ulcers after endoscopic therapy. Am J Gastroenterol 2014; 109: 10051010
[157] El Ouali S, Barkun AN, Wyse J et al. Is routine second-look endoscopy effective after endoscopic hemostasis in acute peptic ulcer bleeding? A meta-analysis. Gastrointest Endosc 2012; 76: 283-292

[158] Imperiale TF, Kong N. Second look endoscopy for bleeding peptic ulcer disease: a decision and cost-effectiveness analysis. J Clin Gastroenterol 2012; 46: 71-75

[159] Chiu PWY, Joeng HKM, Choi CLY et al. High-dose omeprazole infusion compared with scheduled second-look endoscopy for prevention of peptic ulcer rebleeding: a randomized controlled trial. Endoscopy 2016; 48: 717-22

[160] Park S], Park H, Lee YC et al. Effect of scheduled second-look endoscopy on peptic ulcer bleeding: a prospective randomized multicenter trial. Gastrointest Endos 2018; 87: 457-465

[161] Laine L, Spiegel B, Rostom A et al. Methodology for randomized trials of patients with nonvariceal upper gastrointestinal bleeding: recommendations from an international consensus conference. Am J Gastroenterol 2010; 105: 540-550

[162] Lau JYW, Sung JJY, Lam YH et al. Endoscopic retreatment compared with surgery in patients with recurrent bleeding after initial endoscopic control of bleeding ulcer. N Engl J Med 1999; 340: 751-756

[163] Haddara S, Jacques J, Lecleire $S$ et al. A novel hemostatic powder for upper gastrointestinal bleeding: a multicenter study (the "GRAPHE" registry). Endoscopy 2016; 48: 1084-1095

[164] Rodríguez de Santiago E, Burgos-Santamaría D, Pérez-Carazo L et al. Hemostatic spray powder TC-325 for Gl bleeding in a nationwide study: survival and predictors of failure via competing risks analysis. Gastrointest Endosc 2019; 90: 581-590

[165] Lau JYW, Pittayanon R, Wong KT et al. Prophylactic angiographic embolisation after endoscopic control of bleeding to high-risk peptic ulcers: a randomised controlled trial. Gut 2019; 68: 796-803

[166] Gisbert JP, Khorrami S, Carballo F et al. Meta-analysis: Helicobacter pylori eradication therapy vs. anti-secretory non-eradication therapy for the prevention of recurrent bleeding from peptic ulcer. Aliment Pharmacol Ther 2004; 19: 617-629

[167] Ford AC, Delaney BC, Forman D et al. Eradication therapy in Helicobacter pylori positive peptic ulcer disease: systematic review and economic analysis. Am J Gastroenterol 2004; 99: 1833-55

[168] Gisbert JP, Calvet X, Cosme A et al. Long-term follow-up of 1,000 patients cured of Helicobacter pylori infection following an episode of peptic ulcer bleeding. Am J Gastroenterol 2012; 107: 1197-1204

[169] Ford AC, Gurusamy KS, Delaney B et al. Eradication therapy for peptic ulcer disease in Helicobacter pylori-positive people. Cochrane Database Syst Rev 2016; 4: CD003840

[170] Chang SS, Hu HY. Helicobacter pylori eradication within 120 days is associated with decreased complicated recurrent peptic ulcers in peptic ulcer bleeding patients. Gut Liver 2015; 9: 346-352

[171] Hung KW, Knotts RM, Faye AS et al. Factors associated with adherence to Helicobacter pylori testing during hospitalization for bleeding peptic ulcer disease. Clin Gastroenterol Hepatol 2020; 18: 1091 1098

[172] Sverdén E, Brusselaers N, Wahlin K et al. Time latencies of Helicobacter pylori eradication after peptic ulcer and risk of recurrent ulcer, ulcer adverse events, and gastric cancer: a population-based cohort study. Gastrointest Endosc 2018; 88: 242-250

[173] Gisbert JP, Abraira V. Accuracy of Helicobacter pylori diagnostic tests in patients with bleeding peptic ulcer: a systematic review and meta-analysis. Am J Gastroenterol 2006; 101: 848-863

[174] Sánchez-Delgado J, Gené E, Suárez D et al. Has H. pylori prevalence in bleeding peptic ulcer been underestimated? A meta-regression Am J Gastroenterol 2011; 106: 398-405

[175] Lim LG, Ho KY, So JB et al. Diagnosis and treatment of Helicobacter pylori for peptic ulcer bleeding in clinical practice - factors asso- 
ciated with non-diagnosis and non-treatment, and diagnostic yield in various settings. Turk J Gastroenterol 2014; 25: 157-161

[176] Lanas A, Garcia-Rodriguez LA, Arroyo MT et al. Effect of anti-secretory drugs and nitrates on the risk of ulcer bleeding associated with nonsteroidal anti-inflammatory drugs, antiplatelet agents, and anticoagulants. Am J Gastroenterol 2007; 102: 507-515

[177] Bhatt DL, Scheiman J, Abraham NS et al. ACCF/ACG/AHA 2008 expert consensus document on reducing the gastrointestinal risks of antiplatelet therapy and NSAID use: a report of the American College of Cardiology Foundation Task Force on Clinical Expert Consensus Documents. Circulation 2008; 118: 1894-1909

[178] Kwok CS, Nijar RS, Loke YK. Effects of proton pump inhibitors on adverse gastrointestinal events in patients receiving clopidogrel: a systematic review and meta-analysis. Drug Saf 2011; 34: 47-57

[179] Chen J, Chen SY, Lian JJ et al. Pharmacodynamic impacts of proton pump inhibitors on the efficacy of clopidogrel in vivo - a systematic review. Clin Cardiol 2013; 36: 184-189

[180] Kwok CS, Loke YK. Meta-analysis: the effects of proton pump inhibitors on cardiovascular events and mortality in patients receiving clopidogrel. Aliment Pharmacol Ther 2010; 31: 810-823

[181] Siller-Matula JM, Jilma B, Schror K et al. Effect of proton pump inhibitors on clinical outcome in patients treated with clopidogrel: a systematic review and meta-analysis. J Thromb Haemost 2010; 8: 2624-2641

[182] Cardoso RN, Benjo AM, DiNicolantonio J] et al. Incidence of cardiovascular events and gastrointestinal bleeding in patients receiving clopidogrel with and without proton pump inhibitors: an updated meta-analysis. Open Heart 2015; 2: e000248.2

[183] Witt DM, Delate T, Garcia DA et al. Risk of thromboembolism, recurrent hemorrhage, and death after warfarin therapy interruption for gastrointestinal tract bleeding. Arch Intern Med 2012; 172: 1484-1491

[184] Lee JK, Kang HW, Kim SG et al. Risks related with withholding and resuming anticoagulation in patients with non-variceal upper gastrointestinal bleeding while on warfarin therapy. Int J Clin Pract 2012; 66: 64-68

[185] Qureshi W, Mittal C, Patsias I et al. Restarting anticoagulation and outcomes after major gastrointestinal bleeding in atrial fibrillation. Am J Cardiol 2014; 113: 662-668

[186] Staerk L, Lip GY, Olesen JB et al. Stroke and recurrent haemorrhage associated with antithrombotic treatment after gastrointestinal bleeding in patients with atrial fibrillation: nationwide cohort study. BMJ 2015; 351: h5876

[187] Kido K, Scalese MJ. Management of oral anticoagulation therapy after gastrointestinal bleeding: whether to, when to, and how to restart an anticoagulation therapy. Ann Pharmacother 2017; 51: $1000-1007$
[188] Majeed A, Wallvik N, Eriksson J et al. Optimal timing of vitamin K antagonist resumption after upper gastrointestinal bleeding. A risk modelling analysis. Thromb Haemost 2017; 117: 491-499

[189] Hernandez I, Zhang Y, Brooks MM et al. Anticoagulation use and clinical outcomes after major bleeding on dabigatran or warfarin in atrial fibrillation. Stroke 2017; 48: 159-166

[190] Granger CB, Alexander JH, McMurray JJV et al. Apixaban versus warfarin in patients with atrial fibrillation. N Engl J Med 2011; 365: 981 992

[191] Lip GY, Nieuwlaat R, Pisters R et al. Refining clinical risk stratification for predicting stroke and thromboembolism in atrial fibrillation using a novel risk factor-based approach: the euro heart survey on atrial fibrillation. Chest 2010; 137: 263-272

[192] Sandhu RK, Bakal JA, Ezekowitz JA et al. Risk stratification schemes, anticoagulation use and outcomes: the risk-treatment paradox in patients with newly diagnosed non-valvular atrial fibrillation. Heart 2011; 97: 2046-2050

[193] Pisters R, Lane DA, Nieuwlaat $R$ et al. A novel user-friendly score (HAS-BLED) to assess 1-year risk of major bleeding in patients with atrial fibrillation. Chest 2010; 138: 1093-100

[194] Lanas A, Garcia-Rodriguez LA, Arroyo MT et al. Effect of antisecretory drugs and nitrates on the risk of ulcer bleeding associated with nonsteroidal anti-inflammatory drugs, antiplatelet agents, and anticoagulants. Am J Gastroenterol 2007; 102: 507-515

[195] Masso Gonzalez EL, Garcia Rodriguez LA. Proton pump inhibitors reduce the long-term risk of recurrent upper gastrointestinal bleeding: An observational study. Aliment Pharmacol Ther 2008; 28: 629637

[196] Lin KJ, Hernandez-Diaz S, Garcia Rodriguez LA. Acid suppressants reduce risk of gastrointestinal bleeding in patients on antithrombotic or anti-inflammatory therapy. Gastroenterology 2011; 141: 7179

[197] Chan EW, Lau WC, Leung WK et al. Prevention of dabigatran-related gastrointestinal bleeding with gastroprotective agents: A population-based study. Gastroenterology 2015; 149: 586-595

[198] Ray WA, Chung CP, Murray KT et al. Association of proton pump inhibitors with reduced risk of warfarin-related serious upper gastrointestinal bleeding. Gastroenterology 2016; 151: 1105-1112

[199] Moayyedi P, Eikelboom JW, Bosch J et al. Pantoprazole to prevent gastroduodenal events in patients receiving rivaroxaban and/or aspirin in a randomized, double-blind, placebo-controlled trial. Gastroenterology 2019; 157: 403-412

[200] Chan EW, Lau WC, Leung WK et al. Prevention of dabigatran-related gastrointestinal bleeding with gastroprotective agents: A population-based study. Gastroenterology 2015; 149: 586-595 